\title{
Investigation On Stabilization/Solidification Characteristics of Lead Contaminated Soil Using Innovative Composite Model of Cement And Soda Residue
}

\author{
Xiaoyu An \\ Tianjin University \\ Dianjun Zuo \\ Tianjin Research Institute of Water Transport Engineering \\ Fei Wang \\ Tianjin Research Institute of Water Transport Engineering \\ Chao Liang ( $\sim$ leongeoLC@outlook.com ) \\ Tianjin University
}

\section{Research Article}

Keywords: Solidification/stabilization method, lead contaminated soil, Cement, Soda residue, Toxic leaching, Unconfined compressive strength

Posted Date: December 28th, 2021

DOI: https://doi.org/10.21203/rs.3.rs-1025642/v1

License: @ (i) This work is licensed under a Creative Commons Attribution 4.0 International License. Read Full License 


\section{Abstract}

The cement solidification/stabilization method of heavy metal contaminated soils has been promoted in engineering practice and applied on a large scale for site remediation, but it still reveals some scientific problems in the current complex and variable global extreme climate. To solve these problems and explore cement-based soil remediation technology, this study used the waste soda residue produced in large quantities in the "ammonia-soda process" as a composite additive, and established an innovative composite model of cement and soda residue by adding different ratios, which was applied to the remediation experiments of lead-contaminated soil. The innovative composite model solidification/stabilization of cement and soda residue for unconfined compressive strength and toxic leaching properties under different soil environmental conditions were investigated. Moreover, curing and leaching mechanisms are discussed, and future industrial practice was evaluated. The results showed that the addition of soda residue improved the early ( 20 days) unconfined compressive strength (UCS) of the composite curing agent for lead-contaminated soil by an average of $23.1 \% \mathrm{Mpa}$. When the percentage of soda residue composite was $40 \%$, the UCS strength was $0.96 \mathrm{Mpa}$, which reached the maximum. The concentration of $\mathrm{Pb}^{2+}$ in the leachate of the cement-soda residue composite curing agent was greatly reduced (average 3.28 times) compared with that of a single cement in the same situation, with an average leached $\mathrm{Pb}^{2+}$ concentration of $1.87 \mathrm{mg} \cdot \mathrm{L}^{-1}$. This indicates that the addition of alkali residue improved the curing effect. The curing mechanism was divided into four steps, mainly a complex physicochemical reaction between the cement-soda residue composite and soil particles. The leaching mechanism of cement-soda residue to aqueous solution is mainly the consumption of acid ions by alkaline substances. This study will provide scientific data to support potential lead-containing soil in site remediation technologies and future large-scale engineering applications.

\section{Highlights}

1. The cement and soda residue were compounded in a direct homogeneous mixture.

2. The UCS, TCL, curing and leaching mechanisms were researched and discussed.

3. The doping ratios of $S_{b} / S_{d}=20 \%$ and $S_{s} / S_{b}=40 \%$ have the best curing effect.

4. cement-soda residue composite reduces the leaching of $\mathrm{Pb}^{2+}$ by 3.28 times, i.e. $1.87 \mathrm{mg} \cdot \mathrm{L}^{-1}$.

5. The curing mechanism was divided into four steps, mainly a complex physicochemical reaction.

\section{Introduction}

In the past 20 years, with the rapid economic growth of various countries around the world, the urbanization process has been growing at a high rate in many regions (Du et al., 2012). The readjustment of the development positioning and planning of some cities has also prompted a lot of factories to relocate from their original sites, resulting in the legacy of large areas of heavy metal contaminated sites (Li et al., 2014). Soil heavy metal pollution in old factory areas has become a serious environmental problem. Therefore, how to remediate these contaminated lands has become a scientific issue that is of great interest to researchers and engineers alike (Moon et al., 2006). Common site remediation techniques for heavy metal contaminated soils include segregation (Li et al., 2014), soil tilling (Contessi et al., 2020), soil imported from other places (Olson et al., 2013), solidification/stabilization (S/S, Ge et al., 2020), chemical washing (Yang et al., 2020a), electrodynamics (Ouhadi et al., 2020), thermal treatment (Usman et al., 2019), vapor extraction (Shi et al., 2020), bioremediation (Valizadeh et al., 2021), etc. Among them, the solidification/stabilization method is to make the soil form a solidified body with a certain strength, chemical stability and low permeability through physical or chemical methods, and immobilize harmful pollutants in the soil thus reducing the migration, permeation and biological effectiveness of heavy metals in the environment (Wang et al. 2016). S/S is a relatively mature technology with the characteristics of high efficiency, low cost and convenience. Because of these advantages, S/S is widely used in remediation projects of heavy metal contaminated soils (Li et al., 2014). The U.S. Environmental Protection Agency (EPA) considers S/S to be the best technology for the treatment of toxic and hazardous wastes (EPA 1996; Li et al., 2014).

Contamination of soil with heavy metals, especially lead (Pb), is a widespread problem worldwide (Cao et al., 2018). Lead-contaminated soils are distributed the worldwide, with high concentrations of $\mathrm{Pb}$ prevalent in urban, agricultural and mining soils. According to survey data in the last 30 years, Du et al. (2014) found that the economic growth and rapid urbanization of China and other developing countries have led to significant contamination of industrial soils with heavy metals, and Du et al. (2014) believes that lead pollution is one of the most serious environmental problems. Major sources of lead pollution include emissions from the chemical (He et al., 2009), petroleum 
industries and metallurgical industries (Arthy et al., 2017), excessive use of lead-containing pesticides (Han et al., 2018), sewage or sludge (Deng et al., 2016), lead-based paints (Villalobos et al., 2009), and emissions from solid waste incineration and mining operations (Sinegani et al., 2018). For example, a recent national soil quality survey bulletin in China showed that soil heavy metal pollution is widespread throughout the country, and 1.5\% of which are contaminated with Pb (CMEP, 2014). Lead contaminated soil has become a very serious world environmental concern and has received widespread attention from scholars (Wang et al., 2021b). In fact, the U.S. EPA listed $\mathrm{Pb}$ as one of the six most dangerous heavy metal contaminants as early as 1992 (Cameron 1992). This is because the nonbiodegradability, toxicity, persistence and bioaccumulation of lead in the ecosystem are the main threats to human and ecological health (Zhang et al., 2017). After surface soil accumulation, $\mathrm{Pb}$ not only affects the yield and quality of crops, but also may be converted into more toxic compounds by some microorganisms, and enter the human body through the food chain, affecting human health (Wang et al., 2021b). Therefore, remediation of $\mathrm{Pb}$-contaminated soils is necessary to reduce the migration and transformation of $\mathrm{Pb}$ in $\mathrm{Pb}$ contaminated soils (Xi et al., 2014). Based on the above considerations, Pb was selected as the target heavy metal pollutant in this study. In field contaminated soils, the morphology of $\mathrm{Pb}$ is controlled by (a) precipitation of insoluble compounds (Du et al., 2012; Liu et al., 2012), (b) specific adsorption or ion-exchange adsorption on soil mineral matrix (Yan et al., 2017; Yang et al., 2020b), and (c) formation of complexes with organic matter (Jensen et al., 2006). To facilitate the study of cement-based curing agents for the remediation of leadcontaminated soils, lead nitrate $\left(\mathrm{Pb}\left(\mathrm{NO}_{3}\right)_{2}\right)$ is usually chosen as a source of $\mathrm{Pb}$ contamination.

Owing to engineering cost and technical considerations, inorganic materials such as Portland cement (PC) have been widely used in the past as the most common binder in S/S engineering practice because of its relatively low cost and proven effectiveness over the years (Li et al., 2017). There have been many research results on the hydraulic properties, strength and leaching characteristics of cement solidified/stabilized heavy metal contaminated soil (CHMS) (Li et al., 2015). During the cement s/s treatment, the heavy metals finally remain on the surface of the hydrated silicate colloid in the form of hydroxides or complexes (Hou et al., 2018). However, long-term durability practices have also revealed many problems, for example, some cities are in the acid rain zone, where very long annual rainfall and acid rain deposition processes have led to degraded performance and shortened life cycles of building facilities in these cities at low pH values (Sobiecka et al., 2014; Bao et al., 2016). After exposure to acid rain, the performance of CHMS is weakened by the strong acid environment, which leads to the dissolution of cement hydration products such as portlandite and calcium silicate hydrate and the decomposition of the soil matrix (Du et al., 2012). The release and leaching of calcium and silicon from CHMS exacerbates the reduction in strength and other mechanical properties of the cement curing agent as well (Sobiecka et al., 2014; Li et al., 2015). At the same time, a decrease in $\mathrm{pH}$ could cause solidified heavy metals to be re-dissolved, leading to increased leaching and thus undesirable environmental problems (Kundu et al., 2016). In addition, the effects of the dry-wet cycle and other climatic conditions lead to changes in $\mathrm{pH}$, Eh, porosity, permeability, the composition of the cement curing agent, and leaching of heavy metal ions from the solidified soil (Ouhadi et al., 2020). Moreover, together with many other uncertainties, this has led many countries to doubt cement curing agents (Moon et al., 2010). Therefore, there is a strong need to explore new cement-based curing materials to increase confidence in S/S technology (Yin et al., 2020).

Some scholars believe that the research on S/S curing agents in China is relatively late and needs to be further strengthened (Lu et al., 2017). Soda residue (SR) is the waste discharged from the production process of the ammonia-soda process, which has been phased out in developed countries, but is still widely used in many developing countries (Zha et al., 2020a). Due to the production process of soda ash by ammonia-soda method, for every $1 \mathrm{t}$ of soda ash produced, about $0.3 \mathrm{t}$ of soda residue needs to be discharged. In 2016 , for example, according to statistics, China produced 25,583,000 tons of soda ash (Xue et al., 2016), which also means that China discharged $7,765,000$ tons of industrial soda residue in that year. At present, the soda residue mostly adopts the treatment of surface stacking, a large number of soda residue accumulation not only occupies a lot of lands, more importantly, it also causes serious pollution to humans and the environment. Because the soda residue is a strong alkaline material with a high pH value and is corrosive (Zha et al., 2020). After the human body inhaled the dry soda residue powder, it will corrode the respiratory mucosa and endanger human health. Moreover, the soda residue contains a great deal of chloride ions, which will infiltrate into the groundwater with rainwater and pollute the water environment (Wang et al., 2021a). Soda residue has become an important research topic, and many scholars have also conducted a lot of research and exploration on the effective reuse of soda residue (Zha et al., 2020). For example, a significant area of soil in Poland is acidic, so Poland uses soda residue as a soil conditioner to reduce the acidity of the soil while providing the calcium and silicon ions needed for plant growth. In Japan, due to the lack of land area, reclaimed land is used to dispose of soda residue (Kinnarinen et al., 2015). In China, soda residue is reused in various ways, including making bricks and as a building gel material (Xue et al., 2016). The secondary utilization of soda residue as industrial production is not only tedious and cost, but also limited in yield. Therefore, it is urgent to explore the engineering application of soda residue. 
Recently, many scholars have mainly studied the engineering mechanical properties of soda residue and its applicability as an impermeable mat or foundation bedding material for landfills. Moreover, there are fewer studies on the use of soda residue as an additive for cement curing to remediate lead-contaminated soil. Zha et al. (2020) studied the dynamic adsorption of heavy metal ions by soda residue and the influencing factors such as $\mathrm{pH}$ and temperature. The results showed that soda residue has a strong ability to trap heavy metal ions. In addition, much literatures have shown that soda residue has a strong adsorption effect on heavy metal ions (Li et al., 2019), but the variation of lateral limit compressive strength of cement stabilized soil with soda residue as an additive and the mechanism was not analyzed. Therefore, the objectives of this work were as follows: (1) Explore the feasibility of adding soda residue to the cement curing agent, determine the composite mode and ratio of cement-soda residue, and characterize the composite material of cement-soda residue. (2) the unconfined compressive strength of cement-soda residue stabilized Pb-containing soil was investigated by indoor tests. (3) and toxic leaching characteristics of cement-soda residue in solidified lead-contaminated soil was studied. (4) The mechanism of cement-soda residue solidification and stabilization of lead-contaminated soil was discussed, and industrial practical significance was evaluated.

\section{Materials And Methods}

\subsection{Test materials and lead-contaminated soils}

The test lead-free soil samples were obtained from the central eco-city of Binhai New Area, Tianjin, China, and the basic physicochemical properties of the test soils are presented in Table 1. The physical and mechanical properties of these test soils were determined according to the "Standard for Soil Test Methods" of China (GB/T 50123, 1999), with reference to the literature Li et al. (2014). The soil texture used in the test was a pulverized clay soil consisting of $14.61 \%$ clay, $60.85 \%$ sily, $24.53 \%$ sand and $0 \%$ rock, based on dry weight (determined by wet sieve and hydrometer tests) according to the soil texture classification developed by the US Department of Agriculture. According to Li et al. (2017), the pH of the test soil was measured by a pH meter of the Shanghai Leici pH-3E model (Shanghai Yidian Scientific Instruments Co., Ltd.), where the ratio of soil to deionized water was 1:10. Other chemical indicators for the test soils were also obtained according to the "Standard for soil test methods" of China. All chemicals used in this work were purchased from Aladdin Chemistry Co., Ltd. (Shanghai, China), and were analytical grade. Deionized water $\left(18.25 \mathrm{M} \Omega \cdot \mathrm{cm}^{-1}, \mathrm{pH}=6.80\right)$ was used throughout the experiments. All chemicals and solvents are used without further purification. In this work, the pH=7.30 of the test soil was determined to be uncontaminated and the concentrations of other pollutants were lower than the minimum risk values specified in the Risk Control Standard for Soil Contamination of Agricultural Land of China (GB/T 15618, 2018) and the Risk Control Standard for Soil Contamination of Construction Land of China (GB/T 36600, 2018). It means that the test soil is safe and usable (Ge et al., 2020).

Table 1

The physical and chemical characteristics of test soil

\begin{tabular}{|c|c|c|c|c|c|c|c|c|}
\hline \multicolumn{9}{|c|}{ Physical and mechanical indexes } \\
\hline \multirow{2}{*}{$\begin{array}{l}\text { Density } \\
\rho /\left(g * \mathrm{~cm}^{3}\right)\end{array}$} & \multirow{2}{*}{$\begin{array}{l}\begin{array}{l}\text { Moisture } \\
\text { content }\end{array} \\
W / \%\end{array}$} & \multirow{2}{*}{$\begin{array}{l}\text { void } \\
\text { ratio }\end{array}$} & \multirow{2}{*}{ 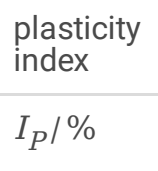 } & \multirow{2}{*}{$\begin{array}{l}\begin{array}{l}\text { modulus of } \\
\text { compression }\end{array} \\
E_{s 0.1-0.2} / \mathrm{Mpa}\end{array}$} & \multicolumn{2}{|c|}{$\begin{array}{l}\text { internal friction } \\
\text { angle }\end{array}$} & \multicolumn{2}{|c|}{ cohesive strength } \\
\hline & & & & & $\phi /\left(^{0}\right)$ & & $\mathrm{c} / \mathrm{kH}$ & \\
\hline 1.83 & 33.0 & 0.949 & 16.1 & 3.48 & 8 & & 5.7 & \\
\hline \multirow[t]{2}{*}{$\mathrm{pH}$} & \multicolumn{8}{|c|}{ Chemical composition/(w/\%) } \\
\hline & $\mathrm{SiO}_{2}$ & $\mathrm{Al}_{2} \mathrm{O}_{3}$ & $\mathrm{Fe}_{2} \mathrm{O}_{3}$ & $\mathrm{TiO}_{2}$ & $\mathrm{CaO}$ & $\mathrm{MgO}$ & $\mathrm{NaCl}$ & $\begin{array}{l}\text { organic } \\
\text { matter }\end{array}$ \\
\hline 7.3 & 61.23 & 18.33 & 6.48 & 0.85 & 1.05 & 3.12 & 2.67 & 6.27 \\
\hline
\end{tabular}

The soil samples were first dried at $105^{\circ} \mathrm{C}$ and $72 \mathrm{~h}$, then ground and finally sieved through a $1 \mathrm{~mm}$ porous sieve for subsequent testing. Considering the inertness of nitrate to cement hydration (Cuisinier et al., 2011), lead nitrate was selected as the source of $\mathrm{Pb}$ contamination and $\mathrm{Pb}\left(\mathrm{NO}_{3}\right)_{2}$ solution because of its high solubility (potential for high cation mobility) and the fact that it does not inhibit the solidification/stabilization reaction. $\mathrm{Pb}\left(\mathrm{NO}_{3}\right)_{2}$ was added to the test soil until the $\mathrm{Pb}^{2+}$ concentration in the soil reached 800,2000 , 5000,25000 and $50000 \mathrm{mg} \cdot \mathrm{kg}^{-1}$, respectively, which represent five concentration levels $\left(\mathrm{W}_{\mathrm{P}}\right)$ of low level (L), medium-low level (ML), medium level $(\mathrm{M})$, medium-high level $(\mathrm{MH})$ and high level $(\mathrm{H})$, respectively. The concentration levels for lead-contaminated soils were set based on the Risk-Based Remediation Goals (RBRG) Guidance Manual for Contaminated Land Management (HongKong EPD, 2007), and these concentration gradients are also within the range of many lead-contaminated soils in China. Finally, deionized water was added to 
the contaminated soil until the water content reached $19.5 \%$. The lead-contaminated soil was mixed well, covered with plastic film, and stewed under standard maintenance conditions $\left(25 \pm 1^{\circ} \mathrm{C}, 95 \%\right.$ humidity) for $10 \mathrm{~d}$ to allow $\mathrm{Pb}\left(\mathrm{NO}_{3}\right)_{2}$ to fully react with the soil. The graphic abstract in this study was shown in Scheme 1.

\subsection{Cement-Soda residue compound}

Ordinary Portland Cement 325 (OPC), as a cementitious material, whose main components are $\mathrm{SiO}_{2}(21.5 \%), \mathrm{Al}_{2} \mathrm{O}_{3}(5.14 \%), \mathrm{Fe}_{2} \mathrm{O}_{3}$ (3.35\%) and $\mathrm{CaO}(64.5 \%)$, was purchased from Tianjin Cement $\mathrm{Co}$. The additive soda residue was collected from the soda residue field in the Dongjiang port area of Tianjin port, and its dry chemical composition include $\mathrm{CaCO}_{3}(43.6 \%), \mathrm{CaSO}_{4}(8.2 \%), \mathrm{CaCl}_{2}(11.2 \%), \mathrm{CaO}$ (7.2\%), $\mathrm{NaCl}(4.3 \%), \mathrm{Al}_{2} \mathrm{O}_{3}(2.6 \%), \mathrm{Fe}_{2} \mathrm{O}_{3}(0.8 \%), \mathrm{SiO}_{2}(6.4 \%), \mathrm{Mg}(\mathrm{OH})_{2}(13.6 \%)$, and $\mathrm{H}_{2} \mathrm{O}(6.3 \%)$. The cement and soda residue were compounded in a direct homogeneous mixture, where the rates of addition of soda residue ("soda residue mass"/"cement mass") in the composite curing agent were $10 \%, 20 \%, 30 \%$ and $40 \%$, respectively. The curing agent used in the subsequent tests was a single cement at $7.5 \%, 10 \%, 15 \%$ and $20 \%$ of the dry soil mass.

\subsection{Characterisation}

Surface morphology of cement and cement-soda residue samples were observed us JSM-6510LV Scanning electron microscope (JEOL Ltd., Tokyo, Japan) with $20 \mathrm{kV}$ scan voltage for Scanning electron microscopy (SEM). All samples were sputtered coated with gold for improving their conductivity before SEM imaging, and the image quality will also enhance (Zhang et al., 2017; Yang et al., 2021). About $0.2 \mathrm{~g}$ cement and cement-soda residue samples sample was degassed for $3 \mathrm{~h}$ at $200^{\circ} \mathrm{C}$ and then determined using $\mathrm{N}_{2}$ as the adsorbate at $77 \mathrm{~K}$ in a relative pressure of $0.05-0.20$ using an ASAP2060 plus specific surface area and pore size analyzer (Micromeritics Instruments Co., Norcross, Georgia, USA). The specific surface area and pore size analysis of samples was analyzed by following the Brunauer, Emmett and Teller method (BET). The infrared spectra were measured with $\mathrm{KBr}$ pellet methods. Fourier-transform infrared (FTIR) data were obtained using KBr pellets and a Vertex70 FTIR spectrometer (Bruker Corp., Billerica, Massachusetts, USA) with 16 scans over $400-4000 \mathrm{~cm}^{-1}$ at a resolution of $2 \mathrm{~cm}^{-1}$. The functional groups were identified by published references (Xi et al., 2014; Li et al., 2020; Ouhadi et al., 2020). The mineral species of biochar were identified using a D/max2400 X-ray powder diffractometer (RIGAKU, Corp., Tokyo, Japan). Grind samples as thin as possible and drip the sample powder as evenly as possible into the sample holder to make it spread out in the window hole. Use the squash method to make the test piece. Vertically squashed the test piece by glass, nonrotatable. It is required that the prepared sample test piece should have a flat surface and be in a plane with the reference plane of the sample holder. Place the test piece in the instrument sample holder. Measured at $0.02 \mathrm{scan}$ step size, $2 \mathrm{deg} \cdot \mathrm{min}^{-1} \mathrm{scan}$ speed, 0.15 receiving slit width, 30-40 kV and 30-40 mA.

\subsection{Experiments}

\subsubsection{S/S treatment of lead-contaminated soil}

The compound curing agents with different mixing ratios were added to the control or test soil according to the matching design scheme in part 2.2 above. Mixing of these materials was performed in a 25-LSPAR type mixer for 15 minutes to ensure uniformity. ASTM Type II deionized water was added to produce a mixture with a 10\% flow rate by using a K-slump tester as specified in ASTM 1362-97 (ASTM 2000). Dissolve lead nitrate in deionized water and mix thoroughly in a magnetic stirrer to obtain a lead nitrate solution. Cement-soda residue complex and dry soil samples were added according to the designed proportioning scheme, stirred well (25min) and loaded into the forming cylinder. After $3 \mathrm{~min}$ static pressing, the sample was demolded into a $5 \mathrm{~cm}$ diameter and $10 \mathrm{~cm}$ high column sample and compacted by shaking table to obtain a good build-up of the mixture. Samples for unconfined compressive strength determination were prepared in triplicate. It was considered appropriate to carry out the mixture in this manner rather than a similar consistency to obtain an indication of the ability of lead nitrate to accelerate or delay the solidification time of the mixture at the same workability. All other aspects of the method remain the same except for the steps below.

\subsubsection{Unconfined compressive strength test (UCS)}

The UCS test is necessary to obtain a rough estimate of the strength of the S/S product and is measured using a universal testing machine (Testometric CXM 500-50 KN) with a loading rate of $0.3 \mathrm{~mm} \cdot \mathrm{min}^{-1}$. The prepared samples are packed in plastic bags, sealed and put into a standard curing box for curing (temperature $20^{\circ} \mathrm{C}$, relative humidity greater than $85 \%$ ), and the curing time is $1 \mathrm{~d}, 3 \mathrm{~d}, 7 \mathrm{~d}$, $14 d, 28 d, 56 d$ and $90 d$. The test method refers to ASTM D2166-06, and the axial strain rate is $1 \% / \mathrm{min}$. To verify the suitability of the S/Streated contaminated soil, a control group test should also be set up, as well as the original test soil sample without the addition of the composite curing agent. The average of the UCS results of three parallel samples is used for the analysis.

Page 5/23 


\subsubsection{Toxicity leaching test (TCL)}

Leaching tests were performed on whole S/S samples according to the procedures of ASTM C1308-08 (ASTM, 2009). The leaching agent was deionized water. Toxicity Characteristic Leaching Procedure (TCLP) and Synthetic Precipitation Leaching Procedure (SPLP) of U.S. EPA were used in toxicity leaching test, and deionized water $(\mathrm{pH}=6.80)$ and high-grade pure glacial acetic acid $(\mathrm{pH}=2.88)$ were used as TCLP extractant respectively. The SPLP extractant uses deionized water to dilute the mixture of nitric acid and sulfuric acid $(\mathrm{pH}=5.00)$. Before the test, the sample with a curing time of 28 days was air-dried, crushed and ground, and passed through a $1 \mathrm{~mm}$ porous sieve; In the experiment, the ratio of liquid to solid was $20: 1$, and the extraction time was $18 \mathrm{~h}$. A constant temperature of $25 \pm 2^{\circ} \mathrm{C}$ was maintained throughout the experiment. After extraction, the final $\mathrm{pH}$ of the leachate was measured and the liquid was separated from the solids by filtration through a $0.45 \mathrm{~mm}$ glass fiber filter. Upon completion of the test, an Agilent 7700 Inductively Coupled Plasma Mass Spectrometer (ICP-MS) was used to determine the metal concentrations in the leachate. Three replicates of each experiment were performed.

\subsection{Data analysis}

In this study, data statistics were calculated using Excel 2019 Pro (Microsoft, USA) and SPSS 22.0 (IBM SPSS Statistics, USA). All pictures were plotted using OriginPro 2019 (OriginLab, USA), and some parameters and numerical simulation were calculated using MATLAB 2019a (MathWorks, USA). In addition, XRD was performed using Jade V6.5 (Materials Data Repository, NIST, USA) to determine the mineral composition of cement and cement-soda residue samples. Some crystals were determined from the ICDD PDF-2 Release 2016 software (the International Centre for Diffraction Data, USA).

\section{Results And Discussion}

\subsection{Characterisation}

Material characterization for the solidify/stabilize (S/S) soils allowed better analysis of their intrinsic physicochemical properties. The SEM micrographs of ordinary Portland cement 325 and soda residue are shown in Fig. 1. It is obvious from Fig. 1(a)-(c) that the microstructure of OPC is characterized by large porosity and structural connection and arrangement. The nature and mineral composition of OPC itself lead to a looser spongy structure on the OPC surface, which is characterized by more pores and a looser structure. With the magnification of SEM, this sparse structure becomes more and more obvious. And there are many fine clay mineral particles attached to the OPC surface. Fig. 1(d)-(f) show the microscopic morphology of SR, which reveals many loose and irregular porous structures with different number and size of pores, similar to sponge-like textures. There are also fine particles on the surface, which are most likely crystals of $\mathrm{C} \mathrm{CaCO}_{3}, \mathrm{CaSO}_{4}, \mathrm{CaO}, \mathrm{Al}_{2} \mathrm{O}_{3}$, and $\mathrm{Mg}(\mathrm{OH})_{2}$. The SEM micrographs of the S/S soils $(\mathrm{Sb} / \mathrm{Sd}=20 \%, 60 \%$ cement $+40 \%$ soda residue, i.e. $\mathrm{CSR})$ and $\mathrm{S} / \mathrm{S}$ soils with $\mathrm{Pb}^{2+}\left(\mathrm{CSR}-\mathrm{Pb}^{2+}\right)$ are shown in Fig. 2. Fig. 2(a)-(c) shows the microscopic morphology of CSR, and it can be observed that CSR has the morphological characteristics of OPC and SR with a loose texture and is rich in porous structure. In addition, a large amount of flocculated hydrated calcium silicate production can also be observed, as well as fine particles, which may be the mineral crystals mentioned above. And the S/S soil has a dense structure with small pores, a fish-scale texture, and comes with multiple layers of flakes, which are the basis for the curing material. It is obvious by observing Fig. 2(d)-(f) that the hydration products of cement and soda residue are generated in large quantities by the reinforced specimens, which are interwoven and filled in the soil voids, making the porosity of the soil decrease and the structure become dense, and the macroscopic performance is increased in strength. And with the increase of the maintenance age, the hydration reaction in the soil is more complete, and the hydration products cover the wrapped soil particles or are scattered between the pores, which makes the strength of the soil further increase. Compared with Fig. 2(a)-(c), the particle distribution is more concentrated, with larger granular crystals present, smoother surface, tighter internal structure, and the appearance of a regular structured mesh, which may be the hydrated calcium silicate or -Si-OA1-O- bonded interconnected gels produced during the curing process of CSR (Yang et al., 2021). These gels could bond the CSR particles to each other into one larger particle (Zhang et al., 2017). In particular, in Fig. 2(f), the reticular or needle-like structures of hydrated calcium silicate $(\mathrm{CSH})$ and calcium aluminate hydrate $(\mathrm{CAH})$ can be clearly observed due to the complex physical and chemical reactions between cement-alkali slag-soil, which generate gels and complexes such as calcium zeolite, C-S-H, and C-A-H.

The BET specific surface area and pore size analysis of the different cured/stabilized soil samples are listed in Table 3. According to the definition of the International Association of Pure and Applied Chemistry (IUPAC), those with a pore diameter less than $2 \mathrm{~nm}$ are called micropores, and those with a pore diameter greater than $50 \mathrm{~nm}$ are called macropores (Wang et al., 2021); those with a pore diameter between 2 and $50 \mathrm{~nm}$ are called mesopores. This shows that the pore structure of cement, soda residue, and CSR (S/S soil) are mainly 
mesoporous materials. It can be seen that the BET specific surface area of SR is the largest $\left(28.6796 \mathrm{~m}^{2} \cdot \mathrm{g}^{-1}\right)$, and the doping of SR into OPC can significantly enhance the BET specific surface area (8 times increase in BET specific surface area and 16 times increase in Langmuir specific surface area) and pore volume (10 times increase in total pore volume, 7 times increase in BJH Adsorption cumulative volume) of the S/S soil (CSR). This implies the ability to adsorb more contaminants such as heavy metal ions, which leads to the cured soil providing more active adsorption sites and porous structure (Li et al., 2019). This result also corroborates with the analysis of SEM in Fig. 1, Which directly indicates that the composite of soda residue into cement is theoretically able to improve the physicochemical properties of the cured soil, especially the porous structure and pore volume. The specific surface area, pore volume, and pore diameter of the cured soil slightly decreased after infiltration of $\mathrm{Pb}^{2+}$. This is direct evidence that $\mathrm{Pb}^{2+}$ is solidified on the surface and internal porous structure of CSR (Xi et al., 2014), occupying a small number of active adsorption sites, leading to a decrease in specific surface area and pore volume, clogging the pore channels and reducing the pore size.

Table 3

BET specific surface area and pore size analysis of different solidify/stabilize soil samples.

\begin{tabular}{|c|c|c|c|c|c|c|c|c|c|}
\hline \multirow{2}{*}{$\begin{array}{l}\text { Sample } \\
\text { type }\end{array}$} & \multicolumn{4}{|c|}{ Surface Area $\left(m^{2} \cdot g^{-1}\right)$} & \multicolumn{3}{|c|}{ Pore Volume $\left(\mathrm{cm}^{3} \cdot \mathrm{g}^{-1}\right)$} & \multicolumn{2}{|c|}{ Pore Size (nm) } \\
\hline & $\begin{array}{l}\text { BET } \\
\text { Surface } \\
\text { Area }\end{array}$ & $\begin{array}{l}\text { Langmuir } \\
\text { Surface } \\
\text { Area }\end{array}$ & $\begin{array}{l}\text { Single point } \\
\text { surface area } \\
\left(p / p_{0}=0.255\right)\end{array}$ & $\begin{array}{l}\text { t-Plot } \\
\text { Micropore } \\
\text { Area }\end{array}$ & $\begin{array}{l}\text { Single } \\
\text { point } \\
\text { adsorption } \\
\text { total pore } \\
\text { volume }\end{array}$ & $\begin{array}{l}\text { BJH } \\
\text { Adsorption } \\
\text { cumulative } \\
\text { volume } \\
\text { (1.70 300 } \\
\text { nm) }\end{array}$ & $\begin{array}{l}\text { t-Plot } \\
\text { micropore } \\
\text { volume }\end{array}$ & $\begin{array}{l}\text { Adsorption } \\
\text { average } \\
\text { pore } \\
\text { diameter }\end{array}$ & $\begin{array}{l}\text { BJH } \\
\text { Adsorption } \\
\text { average } \\
\text { pore } \\
\text { diameter }\end{array}$ \\
\hline OPC & 2.2167 & 15.7532 & 2.1802 & 0.3542 & 0.004145 & 0.010713 & 0.000158 & 7.4965 & 23.9432 \\
\hline SR & 28.6796 & 296.9066 & 27.9132 & 0.1304 & 0.057920 & 0.081120 & 0.000194 & 8.0783 & 11.0466 \\
\hline CSR & 16.3006 & 251.1340 & 15.8500 & 16.5202 & 0.041290 & 0.077745 & 0.000288 & 10.1320 & 17.5043 \\
\hline $\begin{array}{l}\text { CSR- } \\
\mathrm{Pb}^{2+}\end{array}$ & 15.1157 & 218.3564 & 14.7137 & 15.2187 & 0.037594 & 0.074223 & 0.00012 & 9.9485 & 18.3182 \\
\hline
\end{tabular}

FTIR Spectroscopy of the solidify/stabilize (S/S) soils are presented in Fig. 3. Fig. 3(a) obviously displays that this S/S soils

$(\mathrm{Sb} / \mathrm{Sd}=20 \%, 60 \%$ cement $+40 \%$ soda residue, i.e. $\mathrm{CSR})$ is rich in functional groups, which is mainly attributed to the presence of many $\mathrm{OH}\left(3420 \mathrm{~cm}^{-1}\right)$ in the soda residue and $-\mathrm{CH}_{3}$ or $-\mathrm{C}-\mathrm{C}-\left(1000-1070 \mathrm{~cm}^{-1}\right)$ in the cement. The other functional group positions and cements are essentially the same as the soda residues, including $\mathrm{C}-\mathrm{H}\left(2500-2921 \mathrm{~cm}^{-1}\right),-\mathrm{COOH}\left(1800 \mathrm{~cm}^{-1}\right),-\mathrm{C}=0-\left(1450 \mathrm{~cm}^{-1}\right)$, and heterocyclic group $\left(400-900 \mathrm{~cm}^{-1}\right)$. It is noteworthy that the $-\mathrm{OH}$ stretching vibration peak at $3420 \mathrm{~cm}^{-1}$ and the heterocyclic stretching vibration peak at $400-900 \mathrm{~cm}^{-1}$ of CSR are significantly enhanced, which implies that the soda residues is compounded into the cement and that the adsorption properties and oxygen-containing functional groups are improved, making the composite more stable (Li et al., 2017; Ge et al., 2020). The FTIR spectra of the composite CSR after infiltration of $\mathrm{Pb}^{2+}$ are exhibited in Fig. $3(\mathrm{~b})$. The $-\mathrm{OH}\left(3420 \mathrm{~cm}^{-1}\right),-\mathrm{COOH}(1800$ $\left.\mathrm{cm}^{-1}\right)$, and $-\mathrm{C}=0-\left(1450 \mathrm{~cm}^{-1}\right)$ could be clearly observed, and these oxygen-containing functional group stretching vibrational peaks were significantly increased. This most likely suggests that these active sites adsorb $\mathrm{Pb}^{2+}$ or produced gels of hydration products, such as CSH and CAH (Ge et al., 2020; Yang et al., 2021), which corroborates with the SEM and BET characterization results.

X-ray diffraction is capable of detecting the mineral content of a sample and quantifying the mineral content based on the intensity and half-peak width of the diffraction peaks. The XRD patterns of the S/S soils is demonstrated in Fig. 4. It could be noticed from Fig. 4 that OPC, SR and CSR have many minerals, mainly including $\mathrm{SiO}_{2}, \mathrm{CaCO}_{3}, \mathrm{CaSO}_{4}, \mathrm{CaCl}_{2}, \mathrm{CaO}, \mathrm{Al}_{2} \mathrm{O}_{3}, \mathrm{Fe}_{2} \mathrm{O}_{3}$, and $\mathrm{Mg}(\mathrm{OH})_{2}$. The presence of $\mathrm{CSH}$ and CAH crystals was also detected in the samples after the CSR was infiltrated by $\mathrm{Pb}^{2+}$. It meant that complex physicochemical reactions, i.e. hydration reactions, took place between cement and soda residues during the curing period (Zhang et al., 2017; Yang et al., 2021). And a large amount of colloids and complexes such as CSH (hydrated calcium silicate) and CAH (hydrated calcium aluminate) were generated. Moreover, the soda residue is strongly alkaline, and under the alkaline environment and the energy generated by cement hydration, the curing agent reacts with the active $\mathrm{SiO}_{2}$ and $\mathrm{Al}_{2} \mathrm{O}_{3}$ in the soil particles to produce the complex $\mathrm{CaO}_{2} \cdot \mathrm{SiO}_{2} \cdot \mathrm{Al}_{2} \mathrm{O}_{3} \cdot 2 \mathrm{H}_{2} \mathrm{O}(\mathrm{Ge}$ et al., 2020; Yang et al., 2021). This product increases with the age of curing and as the hydration reaction proceeds. It may also make the soil fissures, and some soluble salts or fine soil particles dissolve out of the soil, which leads to the thinning of the soil particle-binding water film, decreasing the attraction and making the soil structure unstable. At the same time, the dissolution of alkaline substances in the pore water will make the stability of hydration products in the soil weaken and gradually be destroyed and dissolved out of the soil, thus leading to the reduction of the unconfined compressive strength of the specimen (Xi et al., 2014; Ge et al., 2020; Yang et al., 2021). The detailed curing mechanism is discussed specifically in section 3.5. 


\subsection{Unconfined compressive strength}

Figure 5 shows the curve of unconfined compressive strength of solidified soil with curing age under different conditions of $S_{b} / S_{d}$ and $W_{p}$, when the curing agent is single cement. It can be seen that the strength of solidified soil gradually increases with the increase of curing age from 0 day to 90 days. Moreover, from Figure 5(a)-1(d), it can be demonstrated that the curing age is from 0 to 14 days, the curve is very steep, which implying a rapid increase in unconfined compressive strength from mean $0.32 \mathrm{Mpa}$ to mean $1.56 \mathrm{Mpa}$. Then curing age from 28 to 90 days, the curve becomes flat, indicating that the unconfined compressive strength grows slowly and basically remains stable from the average value of $1.41 \mathrm{Mpa}$ to $1.87 \mathrm{Mpa}$ average. Furthermore, when the UCS test was performed at a curing age of 0 days, i.e., just after the preparation of the test cylinder samples, it was observed that the initial unconfined compressive strength kept increasing with the increase of the different $S_{b} / S_{d}$ ratio. The initial unconfined compressive strength was maximum when the $S_{b} / S_{d}$ ratio was $20 \%$, with an average value of $0.73 \mathrm{Mpa}$ at different $\mathrm{Pb}^{2+}$ concentration levels. However, with the increase of $\mathrm{Pb}^{2+}$ concentration levels $\left(W_{P}\right)$, the growth trend of solidified soil unconfined compressive strength gradually slows down, and Figure $5(\mathrm{a})-1(\mathrm{~d})$ all have this same phenomenon, which means that the Unconfined compressive strength of the cured soil slowly decreases by $16.3-21.5 \%$ on average as the $\mathrm{Pb}^{2+}$ concentration increases from $0 \mathrm{mg} \cdot \mathrm{kg}^{-1}$ to $50,000 \mathrm{mg} \cdot \mathrm{kg}^{-1}$. Fortunately, although the level of $\mathrm{Pb}^{2+}$ concentration in the soil was increased, the decrease of unconfined compressive strength was basically the same at different $S_{b} / S_{d}$ ratios without much difference. The strength of contaminated soil solidified by cement is lower than that of uncontaminated soil at different curing ages, and with the increase of $\mathrm{Pb}^{2+}$ concentration levels $\left(\mathrm{W}_{\mathrm{P}}\right)$, the degree of reduction is greater, which is consistent with the research results of Tashiro et al (1979), the main reason is that heavy metal oxides such as $P_{b}$ react with cement slurry, which affects the hardening and strength development of cement at the initial hydration stage. In addition, the Unconfined compressive strength of the cured soil increased consistently with increasing single cement (OPC) addition $\mathrm{S}_{b} / \mathrm{S}_{d}$ in lead-contaminated soil at different concentration levels of $\mathrm{Pb}^{2+}$, from $7.5-10 \%$ with an average increase of $6.8 \%$ UCS (MPa), an average increase of $13.3 \%$ UCS (MPa) from 10-15\%, an average increase of $18.7 \%$ UCS (MPa) from 15-20\%. This suggests that the Unconfined compressive strength increases as the addition of OPC $\left(\mathrm{S}_{\mathrm{b}} / \mathrm{S}_{\mathrm{d}}\right)$ to the cured soil increases from $7.5-20 \%$, with a total increase of $32.8 \%$. It also indirectly shows that the curing effect is best when $S_{b} / S_{d}=20$, and this addition ratio $\left(S_{b} / S_{d}=20\right)$ will be applied later in the analysis.

Figure 2 shows the curve of unconfined compressive strength of solidified soil with curing age when the curing age is cement and soda residue, with $S_{b} / S_{d}=20 \%, W_{P}=50000 \mathrm{mg} \cdot \mathrm{kg}^{-1}$ and different $S_{s} / S_{b}$. The test results show that the addition of soda residue improves the early strength of cement-solidified soil, but reduces the long-term strength of solidified soil. The strength of solidified soil increases by $10 \% \sim 25 \%$ in 14 days and decreases by $16.3 \% \sim 23.5 \%$ in 90 days. This turning point occurred near 20 days compared to the $100 \%$ single OPC control group. With the increase of the amount of soda residue, the degree of improvement and reduction is also greater. The reason is that soda residue is a material with high water absorption and high alkalinity (Wang et al., 2021a). The addition of soda residue can improve the hardening speed of cement at the initial hydration stage and the early strength of cement-solidified soil. However, at the same time, soda residue contains $\mathrm{NaCl}$ and other easily soluble salts, which affects the long-term strength development of cementsolidified soil (Zha et al., 2020a). Nevertheless, compared to Fig. 5(d), Fig. 6 clearly shows that the addition of soda residue to the composite curing agent enhances the initial unconfined compressive strength by an average of $23.1 \% \mathrm{Mpa}$. Moreover, the initial unconfined compressive strength increases gradually as the composite proportion of soda residue increases from 0 to $40 \%$, and reaches the maximum when the composite proportion of soda residue is $40 \%$, at which time the unconfined compressive strength is $0.96 \mathrm{Mpa}$. It indicates that the choice of $40 \%$ soda residue and $60 \%$ OPC is ideal up to 20 days of curing age.

\subsection{Strength prediction methods under different Sb/Sd conditions}

In the previous section (section 3.2), the relationship between the unconfined compressive strength of solidified soil and the content of different factors was given. Regression analysis was carried out on the above data, and a calculation method was established to predict the unconfined compressive strength of solidified soil according to the content factors. Processing the data in Fig. 5, taking the test without $W_{p}$ as an example, Fig. 7 shows the law of unconfined compressive strength increasing with $S_{b} / S_{d}$ at different ages. Moreover, as the curing age increases from 1 to 90 days, the unconfined compressive strength also increases gradually as presented in Fig. 7. However, the unconfined compressive strength increased slowly when the curing age was from 1 to 3 days and from 58 to 90 days, and increased rapidly when it was from 3 to 28 days, with an average increase of $50.4 \%$.

It can be seen from Fig. 7 that the non-lateral compressive strength gradually increases with the increase of $S_{b} / S_{d}$, showing a linear growth law, and the growth laws under different ages are basically the same. Then the non-lateral compressive strength $q$ at a certain age $(\mathrm{t})$ can be expressed as:

Page $8 / 23$ 
$q=A \frac{S_{\mathrm{b}}}{S_{\mathrm{d}}}+B$

In formula (1), $q$ is the value of non-lateral compressive strength, $t$ is the age, and $a$ and $b$ are the fitting parameters.

After obtaining the influence relationship of strength with $\mathrm{S}_{b} / S_{d}$, it is necessary to add age factor, so the concept of strength ratio $R$ is introduced, namely

$R=\frac{q_{\mathrm{t}}}{q_{\mathrm{d}}}$

Type of $q_{\mathrm{t}}$ for the unconfined compressive strength under each age, $t$ is different age; $d$ is the unconfined compressive strength of the specimen at a specific age, $q_{\mathrm{d}}$ is the strength base. Taking the test data without Wp as an example, Fig. 8 shows the change rule of strength ratio and age under four different strength standards of $1 d, 7 d, 28 d$ and $90 d$. It can be seen from the results in Fig. 8 that the strength ratio is approximately logarithmic with the age, which can be expressed as:

$R=\ln (t)+D(3)$

In which $C$ and $D$ are fitting constants. It can be seen from the fitting results in Fig. 8 that the unconfined compressive strength of $90 \mathrm{~d}$ age is obviously better in convergence and the error between the fitting curve and the data points is smaller, so the compressive strength of $90 \mathrm{~d}$ is selected as the compressive strength value, $C=0.45$ and $D=0.11$. According to formula (1), the fitting parameters $A$ and $B$ under different Wp contents are summarized as shown in Table 2. Through the regression analysis of the parameters in Table 2, the strength base can be correlated with Wp content, which can be expressed as:

$q_{90}=\left[-0.05 \ln \left(W_{\mathrm{p}}\right)+2.55\right] \frac{S_{\mathrm{b}}}{S_{\mathrm{d}}}+\left[-0.02 \ln \left(W_{\mathrm{p}}\right)+1.04\right]$

Table 2

Fitting parameters of different Wp content conditions $\mathrm{q}_{90}$

\begin{tabular}{|lll|}
\hline $\mathbf{W p}$ & $\boldsymbol{A}$ & $\boldsymbol{B}$ \\
\hline $0.0 \%$ & 3.24 & 1.29 \\
$0.1 \%$ & 3.10 & 1.24 \\
$0.2 \%$ & 2.89 & 1.19 \\
\hline $0.5 \%$ & 2.91 & 1.13 \\
\hline $2.5 \%$ & 2.70 & 1.08 \\
\hline $5.0 \%$ & 2.49 & 1.03 \\
\hline
\end{tabular}

The formula for predicting the strength of solidified soil under different $S_{b} / S_{d}$ and different $W p$ conditions can be obtained by introducing formula (4) into formula (3), namely:

$q_{\mathrm{t}}=0.45 \ln (t)\left\{\begin{array}{l}{\left[-0.05 \ln \left(W_{\mathrm{p}}\right)+2.55\right] \frac{S_{\mathrm{b}}}{S_{\mathrm{d}}}} \\ +\left[-0.02 \ln \left(W_{\mathrm{p}}\right)+1.04\right]\end{array}\right\}+0.11$

Therefore, Formula (5) is the prediction model of unconfined compressive strength of fixed-line soil at any curing age, which will provide more convenience for future in-depth research. Contessi et al., (2020) reported similarly, but did not make predictions and numerical simulations. In the view of Contessi et al. (2020), it is important to be able to predict the unconfined compressive strength in the future direction of S/S technology research.

\subsection{Toxic Leaching Characteristics}

Page 9/23 
Figure 9 shows the solidified soil TCLP and SPLP leachate with curing a age of 28 days under different $S_{b} / S_{d}$ and Pb ${ }^{2+}$ concentration levels when the curing age is single OPC. The experimental test results revealed that that the leaching concentration of $\mathrm{Pb}^{2+}$ gradually decreased with the increase of $\mathrm{S}_{b} / \mathrm{S}_{\mathrm{d}}$ in the leachate of different extraction methods for $\mathrm{Pb}^{2+}$, meanwhile, the initial $\mathrm{Pb}^{2+}$ concentration level was the same. When the initial concentration of $\mathrm{Pb}^{2+}$ in contaminated soil (Wp) was 800, 5000 and 50,000 mg. $\mathrm{kg}^{-1}$, the average reduction of $\mathrm{Pb}^{2+}$ concentration in leachate was $17.5 \%, 34.3 \%$ and $39.2 \%$, respectively. And with the increase of the initial $\mathrm{Pb}^{2+}$ concentration level of the soil, the leaching concentration of $\mathrm{Pb}^{2+}$ also increased gradually in the leachate of different extraction methods for $\mathrm{Pb}^{2+}$, when the same $\mathrm{S}_{\mathrm{b}} / \mathrm{S}_{\mathrm{d}}$ ratio. The concentration of $\mathrm{Pb}^{2+}$ in the leachate increased on average by 7.2, 8.1, 5.7 and 4.3 times when the percentage of OPC added to the contaminated soil $\left(\mathrm{S}_{\mathrm{b}} / \mathrm{S}_{\mathrm{d}}\right.$ ratio) was $7.5 \%, 10 \%, 15 \%$ and $20 \%$. It is noteworthy that when the initial concentration of lead ions in the soil is $50,000 \mathrm{mg} \cdot \mathrm{kg}^{-1}$, the concentrations are all greater than $5 \mathrm{mg} \cdot \mathrm{L}^{-1}$, which exceeds the allowable value of the Standard for Pollution Control of Hazardous Waste Landfill in China. But such high $\mathrm{Pb}^{2+}$ concentrations in contaminated soils are generally rarely seen in real life. It suggests that the higher $\mathrm{Pb}^{2+}$ leaching concentration in the experiments with a single OPC and therefore a composite model is needed to enhance the S/S process (Kundu et al., 2016). By comparing the experimental results of three different extractants, it is obvious that when the extractant is glacial acetic acid, the concentration of $\mathrm{Pb}^{2+}$ in the leaching solution of cement-cured soil is the lowest, when the extractant is deionized water the concentration of $\mathrm{Pb}^{2+}$ in the leaching solution is the highest, and the mixture of nitric acid and sulfuric acid is in the middle. The concentration of $\mathrm{Pb}^{2+}$ in the mixed solution of nitric acid and sulfuric acid is slightly higher than that of deionized water, which is consistent with the research results in reference (Sinegani et al., 2018; Ge et al., 2020; Zha et al., 2020b).

Figure 10 provides the variation of leachate $\mathrm{Pb}^{2+}$ concentration under different cement-soda residue complex ratio $\left(\mathrm{S}_{\mathrm{s}} / \mathrm{S}_{\mathrm{b}}\right)$ conditions for TCLP with curing age of 28 days at $\mathrm{S}_{b} / \mathrm{S}_{\mathrm{b}}=20 \%$ and initial $\mathrm{Pb}^{2+}$ concentration (WP) is $50,000 \mathrm{mg} \cdot \mathrm{kg}^{-1}$. It clearly demonstrated that the $\mathrm{Pb}^{2+}$ concentration in the leachate did not exceed $5 \mathrm{mg} \cdot \mathrm{L}^{-1}$ in all treatment groups; which means that the cement-soda residue complex was more effective in the toxic percolation rate of the lead-contaminated soil compared to the single cement curing agent (Fig. 9c). Indirectly, it illustrated that the solidification and stabilization effect of cement-soda residue complex on lead-contaminated soil was satisfied with the Standard for Pollution Control of Hazardous Waste Landfill in China. Moreover, with the increase of $S_{s} / S_{b}$ ratio from $10-40 \%$, the average concentration of $\mathrm{Pb}^{2+}$ in the leachate gradually decreased from 4.16 to $1.87 \mathrm{mg} \cdot \mathrm{L}^{-1}$. On the whole, the average concentration of $\mathrm{Pb}^{2+}$ in the leachate will gradually decrease by $74.2 \%$ for each $10 \%$ addition of soda residue. In addition, the results of the three extractants exhibited the same trend at different cement-soda residue complex ratio $\left(\mathrm{S}_{\mathrm{s}} / \mathrm{S}_{\mathrm{b}}\right)$ conditions, i.e., glacial acetic acid was the smallest, deionized water was the largest, and the mixture of nitric acid and sulfuric acid was in the middle, with the concentration range not exceeding $0.7 \mathrm{mg} \cdot \mathrm{L}^{-1}$. When the addition dosage of soda residue reached $40 \%$ of the total amount, the $\mathrm{Pb}^{2+}$ concentration decreased on average by 3.28 times compared to the single cement curing agent (Fig. 9c) under the conditions of three extractants, which implied a significant effect of soda residue on the immobilization of heavy metal $\mathrm{Pb}^{2+}$, especially when the initial $\mathrm{Pb}^{2+}$ concentration in the contaminated soil was higher. The adsorption performance for heavy metal $\mathrm{Pb}^{2+}$ ions was greater than that of the single cement control, under channel conditions. This was mainly attributed to the fact that the addition of soda residue increased the $\mathrm{pH}$ of the cured soil powder leachate, stimulating the chemical reaction of heavy metal ion exchange between cement, soda residue and soil, which in turn led to the replacement and consequent immobilization of $\mathrm{Pb}^{2+}$ (Zha et al., 2020a; 2020b; 2021).

\subsection{Solidification mechanism}

Based on the macroscopic test results in this work, the curing and leaching mechanism of Cement-Soda residue composites for solidified/stabilized heavy metal lead-contaminated soil was visualized and speculated by referring to the relevant literature (Zha et al., 2020a; 2020b; 2021; Wang et al. 2021a) and depending on the basic chemical theoretical knowledge. Firstly, when the cement-soda residue solidified soil encounters water, it will undergo hydration reaction and forming a lot of gel (Fig. 1-Fig. 2), which will solidify/stabilize lead ions into the interior of soil particles through the effects of encapsulation, precipitation, complexation and adsorption. Secondly, part of $\mathrm{Pb}^{2+}$ could replace the high-valent $\mathrm{Ca}^{2+}, \mathrm{Mg}^{2+}, \mathrm{Al}^{3+}$ and $\mathrm{Fe}^{3+}$ in the hydration products, and ion-exchange reaction may occur, thereby making the whole mixed system more stable (Fig. 3). During the curing process, cement hydration produces hydration products, such as hydrated calcium silicate $(\mathrm{CSH})$, calcium aluminate hydrate $(\mathrm{CAH})$, and $\mathrm{Ca}(\mathrm{OH})_{2}$, which combine the soil particles and increase the strength of the total soil (Li et al., 2019; Zha et al., 2021). Moreover, in the application of Cement-soda residue composites as curing agents, the soda residue could provide a stable alkaline environment in the S/S process (Fig. 4), and the surface of soda residue enriched with anions needs to adsorb a large number of cations to meet the charge balance. Furthermore, $\mathrm{Ca}(\mathrm{OH})_{2}$ in $\mathrm{pure}$ soda residue could complex with $\mathrm{SiO}_{2}$ and $\mathrm{Al}_{2} \mathrm{O}_{3}$ in clay particles to produce $\mathrm{CSH}$ and $\mathrm{CAH}$ as well. Specifically, the main components of 
soda residue are $\mathrm{CaCO}_{3}$ and $\mathrm{CaO}$, complex and combine with reactive $\mathrm{SiO}_{2}$ in soil particles upon contact with water to produce calcium silicate complexes with large specific surface area, such as $\mathrm{CaSiO}_{3} \cdot \mathrm{CaCO}_{3} \cdot \mathrm{Ca}(\mathrm{OH})_{2} \cdot \mathrm{nH}_{2} \mathrm{O}(\mathrm{CSH}$ gel), which will increase the strength of unconfined compressive strength test early in the curing age (e.g., within 20 days in this study, Fig. 2). In our opinion, complex physicochemical reactions between cement-soda residue composites and soil particles produce a great deal of complexes and gel cements in the soil, which cause the soil samples to become honeycomb aggregates and enhance the strength of the samples (Zhang et al., 2017). The presence of lead ions leads to the reaction with cement to form $\mathrm{Pb}(\mathrm{OH})_{2}$ and lead white $\left(\mathrm{Pb}(\mathrm{OH})_{2} \cdot 2 \mathrm{PbCO}\right)_{3}$, which wrap around the unreacted curing agent particles and separate the binder from the pore water. In addition, soda residue contains many aluminas, magnesium hydroxide and sodium silicate, which will also generate aluminum silicate or magnesium silicate gel during the hydration process. Sodium silicate solution itself curing also provides certain strength for the S/S system later, and the addition of sodium silicate can slow down the rate of water absorption of soda residue-cement-water S/S system, increase the fluidity and prevent segregation (Ouhadi et al., 2021). In this study, the function of deionized water is to dissolve the cement and soda residue, facilitate the transfer between various anions and cations, provide chemical activation energy for hydration and participate in hydration reactions (e.g., $\left.\mathrm{H}^{+}, \mathrm{OH}^{-}\right)$. At a later stage, ionized water may be converted into binding water for the binder and provide an aqueous environment for the polymerization reaction (Fig. 1-Fig. 2). Therefore, the quantity of water directly affects the curing rate and strength magnitude of the crystalline body.

Additionally, Zha et al. (2020a) found that under the heat generated by cement hydration, the reaction between soda residue-cement-soil can produce calcium zeolite with a large specific surface area, which is known to be an efficient adsorbent with a large specific surface area. In summary, the main reaction equation is presumed to be as follows:

(1) In the first stage, the S/S reaction process produced hydrated calcium silicate gel (C-S-H). The process occurs on the surface where the soda residue and cement are in contact with the aqueous solution, uniformly distributed in the system (Fig. 1-Fig. 4). The reaction process is expressed as follows:

$\mathrm{CaCO}_{3}+\mathrm{Ca}(\mathrm{OH})_{2} \rightarrow \mathrm{CaCO}_{3} \cdot \mathrm{Ca}(\mathrm{OH})_{2} \downarrow(6)$

$\mathrm{CaCO}_{3}+2 \mathrm{CaO}+\mathrm{SiO}_{2}+(\mathrm{n}+1) \mathrm{H}_{2} \mathrm{O} \rightarrow \mathrm{CaSiO}_{3} \cdot \mathrm{CaCO}_{3} \cdot \mathrm{Ca}(\mathrm{OH})_{2} \cdot \mathrm{nH}_{2} \mathrm{O} \downarrow(7)$

$\mathrm{SiO}_{2}+\mathrm{Ca}(\mathrm{OH})_{2}+\mathrm{nH}_{2} \mathrm{O} \rightarrow \mathrm{CaO} \cdot \mathrm{SiO}_{2} \cdot(\mathrm{n}+1) \mathrm{H}_{2} \mathrm{O} \downarrow(8)$

$\mathrm{Al}_{2} \mathrm{O}_{3}+\mathrm{Ca}(\mathrm{OH})_{2}+\mathrm{nH}_{2} \mathrm{O} \rightarrow \mathrm{CaO} \cdot \mathrm{Al}_{2} \mathrm{O}_{3} \cdot(\mathrm{n}+1) \mathrm{H}_{2} \mathrm{O} \downarrow(9)$

$\mathrm{Na}_{2} \mathrm{SiO}_{3}+\mathrm{CaCl}_{2}+\mathrm{nH}_{2} \mathrm{O} \rightarrow \mathrm{CaSiO}_{3} \cdot \mathrm{nH}_{2} \mathrm{O} \downarrow+2 \mathrm{NaCl}(10)$

$\mathrm{Na}_{2} \mathrm{SiO}_{3}+\mathrm{Ca}(\mathrm{OH})_{2}+\mathrm{nH}_{2} \mathrm{O} \rightarrow \mathrm{CaSiO}_{3} \cdot \mathrm{nH}_{2} \mathrm{O} \downarrow+2 \mathrm{NaOH}(11)$

$\mathrm{Na}_{2} \mathrm{SiO}_{3}+\mathrm{CaSO}_{4}+\mathrm{nH}_{2} \mathrm{O} \rightarrow \mathrm{CaSiO}_{3} \cdot \mathrm{nH}_{2} \mathrm{O} \downarrow+\mathrm{Na}_{2} \mathrm{SO}_{4}(12)$

(2) In the second stage, the S/S reaction process produces silica-aluminate polymers ( $\mathrm{N}-\mathrm{A}-\mathrm{S}-\mathrm{H}$, also known as $\mathrm{CAH}$ ). The $\mathrm{NaOH}$ generated by the above reaction and the alkaline $\mathrm{OH}$ - of the soda residue itself act on the surface of the lime and are excited to form silicaaluminate polymers of different polymerization degrees (N-A-S-H) by a process of dissolution and polymerization (Sobiecka et al., 2014; Ge et al., 2020). The reaction rate of this process is closely related to the basicity of the system. The reaction process can be expressed as follows:

$\mathrm{n}\left(\mathrm{SiO}_{2} \cdot \mathrm{Al}_{2} \mathrm{O}_{3}\right)+\mathrm{nSiO}_{2}+4 \mathrm{nH}_{2} \mathrm{O}\left(\mathrm{Na}^{+}\right) \cdot(-\mathrm{Si}-\mathrm{O}-\mathrm{Al}-\mathrm{O}-\mathrm{Si}-\mathrm{O})_{\mathrm{n}}(13)$

(3) In the third stage, as the calcium-containing component of the soda residue reacts with sodium silicate solution to generate hydrated calcium silicate gel. The strength in the later stage is further improved by the cement being excited by alkali and generating a silicaaluminate polymer gel on its surface through the process of dissolution and re-polymerization, and the increase is large. At this time, the products in the system are C-S-H gel and N-A-S-H gel coexisting.

(4) In the fourth stage, appropriate changes in environmental conditions can promote the transfer of $\mathrm{Na}+$, the formation of C-S-H gels and $\mathrm{N}-\mathrm{A}-\mathrm{S}-\mathrm{H}$ gels. In addition, the self-curing phenomenon of sodium silicate solution at room temperature for $20 \mathrm{~d}$ is due to the hydrolysis of sodium silicate itself to produce silica gel, which also provides some strength for the later stage. The reaction equation is as follows: 
$\mathrm{Na}_{2} \mathrm{SiO}_{3}+(\mathrm{m}+1) \mathrm{H}_{2} \mathrm{O} \rightarrow \mathrm{SiO}_{2}($ active $)+\mathrm{mH}_{2} \mathrm{O}+2 \mathrm{NaOH}(14)$

In the toxic leaching process (TCLP), the leaching mechanism of cement-soda residue to the solution is mainly the consumption of acid ions by alkaline substances. Firstly, the hydration of cement soil produces a large number of hydration products calcium hydroxide, which can consume part of the $\mathrm{H}^{+}$in the leachate ( $\mathrm{Li}$ et al., 2017). Secondly, $\mathrm{CaCO}_{3}$, the main component of soda residue, can react with $\mathrm{H}^{+}$in the acid solution, thus weakening the erosion damage of the acid solution on the gel (Bao et al., 2016; Cao et al., 2018). In addition, under the heat generated by cement hydration, the reaction between soda residue-cement-soil can generate calcium zeolite, which has a large specific surface area and can adsorb $\mathrm{H}^{+}$in the acid solution and buffer the damage of the acid solution to the curing system.

\subsection{Future industrial practice significance and evaluation}

There are also some examples of engineering practices here, which are highly meaningful for us to inspire in-depth applied research. Zha et al. (2021) concluded that cement and soda residue (CSR) has been proven to be an effective binder for treating heavy metal contaminated soils, and its durability is its most important property. Zha et al. (2021) investigated the leaching behavior of the consolidated/stabilized CSR under acid rain conditions. The leaching behavior of $\mathrm{Zn}$-contaminated soils was investigated under acid rain conditions, and it was found that the UCS of the cured soil samples decreased and the permeability coefficient increased, while the Zn concentration in the filtrate always met the applicable standard Chinese National Environmental Quality Standard III $\left(<1 \mathrm{mg} \cdot \mathrm{L}^{-1}\right)$. Wang et al. (2021a) reported that soda residue and cement were used as limy materials for synthesizing four clinker binders, and then investigated the effects of temperature and number of washes on chloride ions in soda-cement, showing that the fracture and crushing strengths of clinker binders synthesized from soda-cement increased from 4.3 to $26.9 \mathrm{MPa}$ to 7.2 and $52.7 \mathrm{MPa}$ at $30 \mathrm{~d}$, respectively, and reusing soda residue could reduce pollution emission and the management cost of enterprises. Zha et al. (2020b) evaluated the UCS strength, toxic leaching and microstructure of cement/soda residue treated $\mathrm{Cr}^{3+}$ contaminated soil (initial concentration up to 10,000 $\left.\mathrm{mg} \cdot \mathrm{kg}^{-1}\right)$, Zha believed that the unconfined compressive strength (UCS) increased with increasing curing time, binder content and binder ratio, and the leached $\mathrm{Cr}^{3+}$ concentration decreased to a minimum of $1.93 \mathrm{mg} \cdot \mathrm{L}^{-1}$. It is very similar to our results, but the average leaching concentration was lower than $1.93 \mathrm{mg} \cdot \mathrm{L}^{-1}$ for $\mathrm{Pb}^{2+}$ initial concentration up to $50,000 \mathrm{mg} \cdot \mathrm{kg}^{-1}$ in our study, which shows that the cement-soda residue composite curing agent is more effective in curing $\mathrm{Pb}^{2+}$ in soil.

This work combines the latest research progress of current cement solidification/stabilization soil remediation technology with the actual treatment of industrial soda residue materials, and based on the characteristics of cement and soda residue, a new method of cement soda residue solidification/stabilization of soil contaminated by heavy metal lead is formed by using soda residue instead of partial cement for soil reinforcement based on the traditional cement reinforcement, which not only meets the actual requirements of engineering, but also this method not only meets the practical requirements of the project, but also solves the problems of soda residue piling and environmental pollution, and solves the problem of lack of high-quality filler in soft soil areas (Li et al., 2014; 2015). It provides some guidance for the application in engineering and the amount of admixture. Therefore, this study has very great economic and environmental benefits and has a broad application prospect, which is of great value and significance for industrial upgrading and transformation to a resource-saving society. Although the remediation of heavy metal contaminated soil sites in China is later than that in traditional developed countries, many large scale remediation projects for heavy metal contaminated sites have emerged in recent years due to the increasing emphasis on heavy metal contamination in soils on the one hand (Xi et al., 2014; Yang et al., 2020b), and the increasing scarcity of land resources and the change in national thinking about urban development on the other. This detailed study is a good demonstration and reference for the subsequent implementation of such technologies.

\section{Conclusion}

In this work, soda residue was used as an additive to conventional cement curing agent, and an innovative compounding model and addition ratio were explored, and the UCS strength and toxic leaching characteristics of cement-soda residue cured soil containing lead contamination were investigated, the effect of soda residue on cured soil was analyzed, the curing mechanism was explored, and future industrial practice was evaluated. The following conclusions were drawn: (1) The unconfined compressive strength of cement-soda residue composite curing agent on lead-contaminated soil increased with the increase of curing age, and basically stabilized at the average value of 1.41-1.87 Mpa, with a total increase of $32.8 \%$. However, it decreases with the increase of lead contamination source content, decreasing by $16.3 \%-21.5 \%$. The best curing effect was achieved when the mass ratio of cement to cured soil was $20 \%$. (2) The addition of soda residue improved the early ( 20 days) USC strength of the composite curing agent for lead-contaminated soil by an average of $23.1 \% \mathrm{Mpa}$; however, it reduced the later strength of the cement-cured soil. When the proportion of alkali-slag composite is $40 \%$, the lateral limit compressive strength is $0.96 \mathrm{Mpa}$, which reaches the maximum. (3) The concentration of $\mathrm{Pb}^{2+}$ in the leachate of

Page $12 / 23$ 
cement-cured soil decreased with the increase of curing age, but increased with the increase of $\mathrm{Pb}$ contaminant content. the extracted concentration of $\mathrm{Pb}^{2+}$ was the lowest in glacial acetic acid and the highest in distilled water. (4) The concentration of $\mathrm{Pb}^{2+}$ in the leachate of the cement-soda residue composite curing agent was greatly reduced (by an average of 3.28 times) compared with that of a single cement in the same situation, with an average leached $\mathrm{Pb}^{2+}$ concentration of $1.87 \mathrm{mg} \cdot \mathrm{L}^{-1}$. This indicates that the addition of alkali residue improved the curing effect. (5) The curing mechanism was divided into four steps, mainly a complex physicochemical reaction between the cement-soda residue composite and soil particles, which produced a large number of complexes and gel cements in the soil, making the S/S system more stable and reducing the leaching of $\mathrm{Pb}^{2+}$. (6) The leaching mechanism of cement-soda residue to aqueous solution is mainly the consumption of acid ions by alkaline substances. Therefore, this study has very great economic and environmental benefits and has broad application prospects, which are of great value and significance for industrial upgrading as well as transformation to a resource-saving society.

\section{Declarations}

\section{Acknowledgments}

The authors wish to express their sincere thanks to the Fundamental Research Funds for the Central Public Welfare Research Institutes (No.tks20200309). We also would like to thank Aischolar (https://www.ais.cn/) for English language editing.

\section{Authors' contributions}

Xiaoyu AN: Investigation, Conceptualization, Methodology, Analysis and interpretation of the data, Writing. Dianjun ZUO: Software, Validation, Formal analysis. Chao LIANG: Resources, Supervision, Writing-review and editing.

\section{Statements and Declarations}

Competing interests The authors declare that they have no conflict of interest.

Ethical approval Not applicable

Consent to participate Not applicable

Availability of data and materials Not applicable

\section{References}

1. Arthy M, Phanikumar BR (2017) Solidification/stabilization of tannery sludge with iron-based nanoparticles and nanobiocomposites. Environ Earth Sci 76. doi:10.1007/s12665-017-6478-z

2. ASTM (2000) Annual Book of ASTM Standards, Section Four: Construction, vol. 04.01. American Society of Testing and Materials (ASTM)

3. ASTM, C1308-08 (2009) Standard Method for Accelerated Leach Test for Diffusive Release from Solidified Waste and a Computer Program to Model Diffusive, Fractional Leaching from Cylindrical Waste Forms. ASTM International

4. Bao J, Wang L, Xiao M (2016) Changes in speciation and leaching behaviors of heavy metals in dredged sediment solidified/stabilized with various materials. Environ Sci Pollut Res 23:8294-8301. doi:10.1007/s11356-016-6184-5

5. Cameron RE (1992) Guide to site and soil description for hazardous waste characterization. Metals. A Guide for Site and Soil Description in Hazardous Waste Site Characterization

6. Cao Z, Xiang L, Peng E, Li K (2018) Experimental Study on Electrical Resistivity of Cement-Stabilized Lead-Contaminated Soils. Advances in Civil Engineering 2018. doi:10.1155/2018/4628784

7. CMEP A (2014) Bulletin on National Survey of Soil Contamination. Ministry of Environmental Protection, People's Republic of China. Reference No.000014672/2014e00351

8. Contessi S, Calgaro L, Dalconi MC, Bonetto A, Bellotto MP, Ferrari G, Marcomini A, Artioli G (2020) Stabilization of lead contaminated soil with traditional and alternative binders. J Hazard Mater 382. doi:10.1016/j.jhazmat.2019.120990

9. Deng W, Li X, An Z, Yang L (2016) The occurrence and sources of heavy metal contamination in peri-urban and smelting contaminated sites in Baoji, China. Environ Monit Assess 188. doi:10.1007/s10661-016-5246-y doi:10.1016/j.jhazmat.2014.02.002 
10. Du Y, Jiang N, Shen S, Jin F (2012) Experimental investigation of influence of acid rain on leaching and hydraulic characteristics of cement-based solidified/stabilized lead contaminated clay. J Hazard Mater 225:195-201. doi:10.1016/j.jhazmat.2012.04.072

11. Du Y-J, Wei M-L, Reddy KR, Liu Z-P, Jin F (2014) Effect of acid rain pH on leaching behavior of cement stabilized lead-contaminated soil. J Hazard Mater 271:131-140

12. EPA US (1996) Test methods for evaluating solid wastes, physical/chemical methods, SW-846. Office of Solid Waste and Emergency Response, Washington, DC

13. Ge S, Pan Y, Zheng L, Xie X (2020) Effects of organic matter components and incubation on the cement-based stabilization/solidification characteristics of lead-contaminated soil. Chemosphere 260. doi:10.1016/j.chemosphere.2020.127646

14. Han Z, Guo X, Zhang B, Liao J, Nie L (2018) Blood lead levels of children in urban and suburban areas in China (1997-2015): Temporal and spatial variations and influencing factors. Sci Total Environ 625:1659-1666. doi:10.1016/j.scitotenv.2017.12.315

15. He K, Wang S, Zhang J (2009) Blood lead levels of children and its trend in China. Sci Total Environ 407:3986-3993. doi:10.1016/j.scitotenv.2009.03.018

16. HongKong EPD, December (2007) Guidance Manual for Use of Risk-based Remediation Goals for Contaminated Land Management. Environmental Protection Department, HKSAR Government

17. Hou J, Li H, Liu L (2018) An experimental study on microstructure of leachate-polluted stabilized clay. Environ Earth Sci 77. doi:10.1007/s12665-018-7822-7

18. Jensen PE, Ottosen LM, Pedersen AJ (2006) Speciation of Pb in industrially polluted soils. Water Air and Soil Pollution $170: 359-382$. doi:10.1007/s11270-005-9008-7

19. Kinnarinen T, Lubieniecki B, Holliday L, Helsto J-J, Hakkinen A (2015) Enabling safe dry cake disposal of bauxite residue by deliquoring and washing with a membrane filter press. Waste Manag Res 33:258-266. doi:10.1177/0734242x14567503

20. Kundu S, Aggarwal A, Mazumdar S, Dutt KB (2016) Stabilization characteristics of copper mine tailings through its utilization as a partial substitute for cement in concrete: preliminary investigations. Environ Earth Sci 75. doi:10.1007/s12665-015-5089-9

21. Li J, Poon CS (2017) Innovative solidification/stabilization of lead contaminated soil using incineration sewage sludge ash. Chemosphere 173:143-152. doi:10.1016/j.chemosphere.2017.01.065

22. Li J, Xue Q, Wang P, Li Z, Liu L (2014) Effect of drying-wetting cycles on leaching behavior of cement solidified lead-contaminated soil. Chemosphere 117:10-13. doi:10.1016/j.chemosphere.2014.05.045

23. Li J-s (2019) Leaching Behavior and Mechanism of S/S-Treated Pb-Contaminated Soil Under Erosive Environment. Evolution Mechanism on Structural Characteristics of Lead-Contaminated Soil in the Solidification/Stabilization Process. pp131-156

24. Li J-s, Xue Q, Wang P, Li Z-z, Du Y-j (2015) Solidification/stabilization of lead-contaminated soil using cement and waste phosphorus slag. Environ Prog Sustain Energy 34:957-963. doi:10.1002/ep.12074

25. Li J-S, Xue Q, Wang P, Zhang T-T, Zhao Y (2016) Comparison of solidification/stabilization of lead contaminated soil between magnesia-phosphate cement and ordinary portland cement under the same dosage. Environ Prog Sustain Energy 35:88-94. doi:10.1002/ep.12204

26. Liu R, Wang M, Chen W, Peng C (2016) Spatial pattern of heavy metals accumulation risk in urban soils of Beijing and its influencing factors. Environ Pollut 210:174-181. doi:10.1016/j.envpol.2015.11.044

27. Lu Q, Xiao H, Du Y, Du D (2017) Using CaO to stabilize arsenic sulfide slag by moderate temperature calcination. Environ Earth Sci 76. doi:10.1007/s12665-017-6566-0

28. Moon DH, Dermatas D (2006) An evaluation of lead leachability from stabilized/solidified soils under modified semi-dynamic leaching conditions. Eng Geol 85:67-74. doi:10.1016/j.enggeo.2005.09.028

29. Moon DH, Lee J-R, Grubb DG, Park J-H (2010) An assessment of Portland cement, cement kiln dust and Class C fly ash for the immobilization of Zn in contaminated soils. Environ Earth Sci 61:1745-1750. doi:10.1007/s12665-010-0596-1

30. Olson NC, Gulliver JS, Nieber JL, Kayhanian M (2013) Remediation to improve infiltration into compact soils. J Environ Manage 117:85-95. doi:10.1016/j.jenvman.2012.10.057

31. Ouhadi VR, Yong RN, Deiranlou M (2021) Enhancement of cement-based solidification/stabilization of a lead-contaminated smectite clay. J Hazard Mater 403. doi:10.1016/j.jhazmat.2020.123969

32. Shi J, Yang Y, Li J, Xi B, Wang Y, Wang Y, Tang J (2020) A study of layered-unlayered extraction of benzene in soil by SVE. Environ Pollut 263. doi:10.1016/j.envpol.2020.114219 
33. Sinegani MS, Sinegani AAS, Hadipour M (2018) Sources and spatial distribution of lead (Pb) and cadmium (Cd) in saline soils and sediments of Mighan Playa (Iran). Lakes \& Reservoirs Research and Management 23:117-129. doi:10.1111//re.12208

34. Sobiecka E, Obraniak A, Antizar-Ladislao B (2014) Influence of mixture ratio and pH to solidification/stabilization process of hospital solid waste incineration ash in Portland cement. Chemosphere 111:18-23. doi:10.1016/j.chemosphere.2014.03.057

35. Tashiro C, Oba J, Akama K (1979) The effects of several heavy metal oxides on the formation of ettringite and the microstructure of hardened ettringite. Cem Concr Res 9:303-308. doi:https://doi.org/10.1016/0008-8846(79)90122-4

36. Usman M (2019) Comment on "thermal remediation alters soil properties - A review". J Environ Manage 249. doi:10.1016/j.jenvman.2017.12.057

37. Valizadeh S, Lee SS, Baek K, Choi YJ, Jeon B-H, Rhee GH, Andrew Lin K-Y, Park Y-K (2021) Bioremediation strategies with biochar for polychlorinated biphenyls (PCBs)-contaminated soils: A review. Environ Res 200:111757-111757. doi:10.1016/j.envres.2021.111757

38. Villalobos M, Merino-Sanchez C, Hall C, Grieshop J, Gutierrez-Ruiz ME, Handley MA (2009) Lead (II) detection and contamination routes in environmental sources, cookware and home-prepared foods from Zimatlan, Oaxaca, Mexico. Sci Total Environ 407:28362844. doi:10.1016/j.scitotenv.2008.12.059

39. Wang P, Xue Q, Li J-S, Zhang T-T (2016) Effects of pH on leaching behavior of compacted cement solidified/stabilized lead contaminated soil. Environ Prog Sustain Energy 35:149-155. doi:10.1002/ep.12218

40. Wang Q, Li J, Zhang J, Wu P, Lyu X, Hu S, Qiu J, Liu X, Yu H (2021a) Reuse of the soda sludge dealt with water washing as a supplementary material for the synthesis of clinker binders. J Clean Prod 295. doi:10.1016/j.jclepro.2021.126433

41. Wang T, Zheng J, Liu H, Peng Q, Zhou H, Zhang X (2021b) Adsorption characteristics and mechanisms of Pb(2+) and Cd(2+) by a new agricultural waste-Caragana korshinskii biomass derived biochar. Environ Sci Pollut Res Int 28:13800-13818. doi:10.1007/s11356-020-11571-9

42. Xi Y, Wu X, Xiong H (2014) Solidification/Stabilization of Pb-contaminated Soils with Cement and Other Additives. Soil Sediment Contam 23:887-898. doi:10.1080/15320383.2014.890168

43. Xue S, Kong X, Zhu F, Hartley W, Li X, Li Y (2016) Proposal for management and alkalinity transformation of bauxite residue in China. Environ Sci Pollut Res 23:12822-12834. doi:10.1007/s11356-016-6478-7

44. Yan K, Dong Z, Wijayawardena MAA, Liu Y, Naidu R, Semple K (2017) Measurement of soil lead bioavailability and influence of soil types and properties: A review. Chemosphere 184:27-42. doi:10.1016/j.chemosphere.2017.05.143

45. Yang J, Wang J, Qiao P, Zheng Y, Yang J, Chen T, Lei M, Wan X, Zhou X (2020a) Identifying factors that influence soil heavy metals by using categorical regression analysis: A case study in Beijing, China. Frontiers of Environmental Science \& Engineering 14. doi:10.1007/s11783-019-1216-2

46. Yang Z, Wang Y, Li D, Li X, Liu X (2020b) Influence of Freeze-Thaw Cycles and Binder Dosage on the Engineering Properties of Compound Solidified/Stabilized Lead-Contaminated Soils. Int J Environ Res Public Health 17. doi:10.3390/ijerph17031077

47. Yang Z, Wang Y, Li X, Ren S, Xu H, Chang J (2021) The effect of long-term freeze-thaw cycles on the stabilization of lead in compound solidified/stabilized lead-contaminated soil. Environ Sci Pollut Res Int 28:37413-37423. doi:10.1007/s11356-021-13401y

48. Yin C-Y, Bin Mahmud H, Shaaban MG (2006) Stabilization/solidification of lead-contaminated soil using cement and rice husk ash. J Hazard Mater 137:1758-1764. doi:10.1016/j.jhazmat.2006.05.013

49. Zha F, Liu C, Kang B, Yang X, Zhou Y, Yang C (2021) Acid rain leaching behavior of Zn-contaminated soils solidified/stabilized using cement-soda residue. Chemosphere 281:130916. doi:10.1016/j.chemosphere.2021.130916

50. Zha F, Wang H, Xu L, Yang C, Kang B, Chu C, Deng Y, Tan X (2020a) Initial feasibility study in adsorption capacity and mechanism of soda residue on lead (II)-contaminated soil in solidification/stabilization technology. Environ Earth Sci 79. doi:10.1007/s12665-02008990-9

51. Zha F, Zhu F, Kang B, Xu L, Deng Y, Yang C, Chu C (2020b) Experimental Investigation of Cement/Soda Residue for Solidification/Stabilization of Cr-Contaminated Soils. Advances in Civil Engineering 2020:1-13. doi:10.1155/2020/8890149

52. Zhang D, Cao Z, Zhang T, Su X (2017) Effect of carbonation on leaching behavior, engineering properties and microstructure of cement-stabilized lead-contaminated soils. Environ Earth Sci 76. doi:10.1007/s12665-017-7071-1

\section{Scheme}

Page 15/23 


\section{Figures}

\section{Figure 1}

SEM micrographs of ordinary Portland cement 325 (OPC) and soda residue (SR). (a) OPC with 500 times magnification, (b) OPC with 2000 times magnification, (c) OPC with 10000 times magnification, (d) SR with 1000 times magnification, (e) SR with 5000 times magnification, (f) SR with 20000 times magnification.

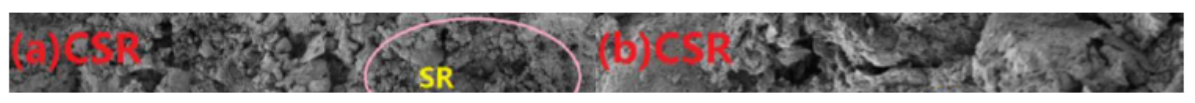

\section{Figure 2}

SEM micrographs of the solidify/stabilize (S/S) soils (cement and soda residue, CSR) and S/S soils with $\mathrm{Pb}^{2+}\left(\mathrm{CSR}-\mathrm{Pb}^{2+}\right.$ ). (a) CSR with 500 times magnification, (b) CSR with 2000 times magnification, (c) CSR with 10000 times magnification, (d) CSR-Pb ${ }^{2+}$ with 500 times magnification, (e) CSR-Pb ${ }^{2+}$ with 5000 times magnification, (f) $C S R-\mathrm{Pb}^{2+}$ with 20000 times magnification. 


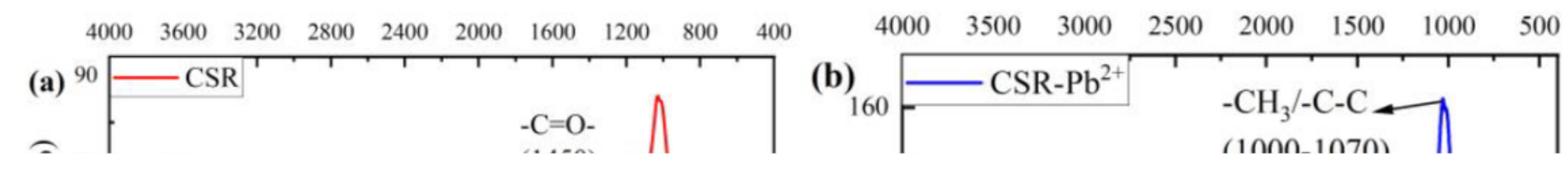

\section{Figure 3}

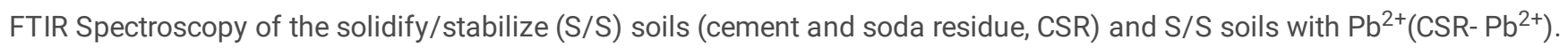




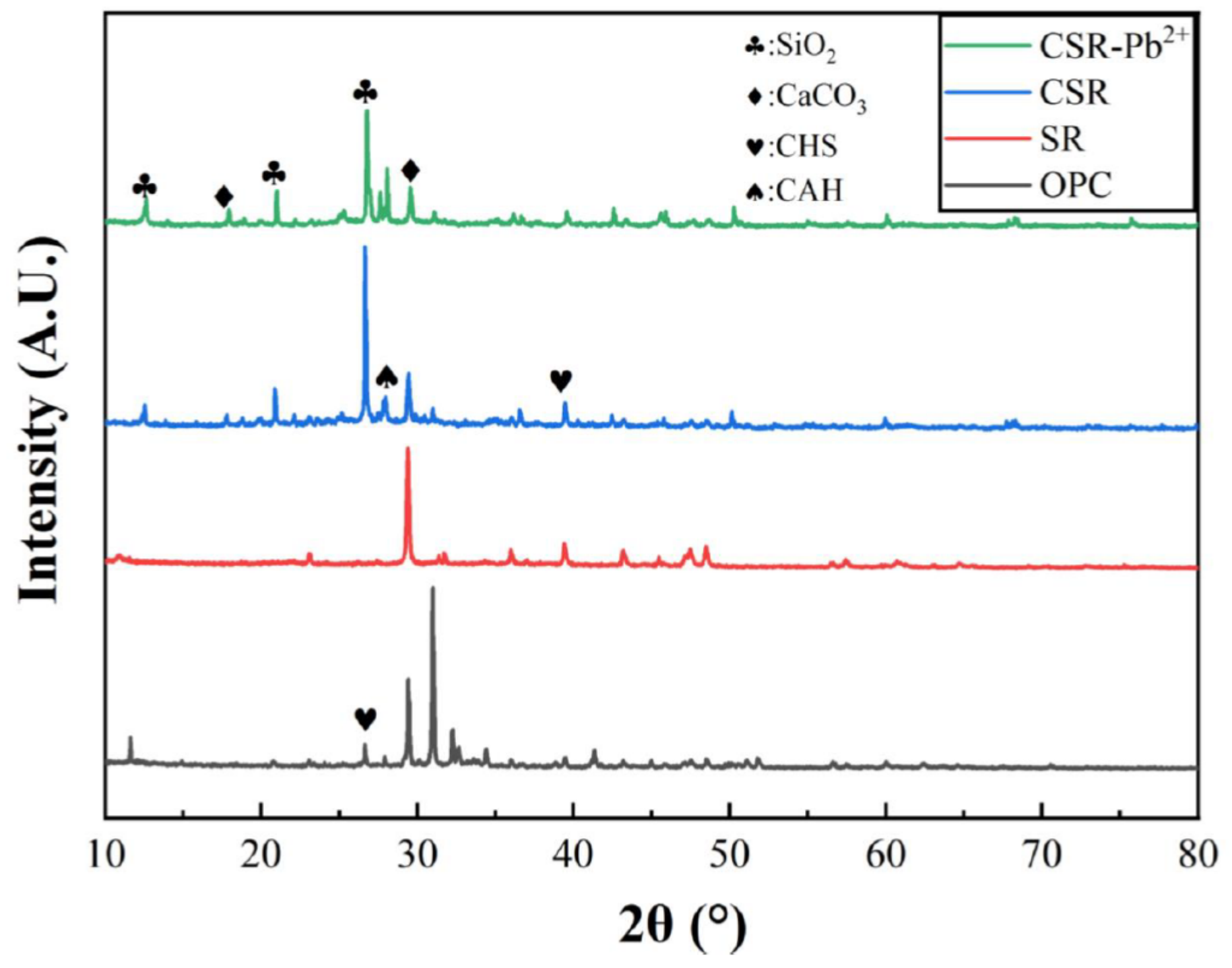

Figure 4

XRD patterns of the solidify/stabilize (S/S) soils (cement and soda residue, CSR) and S/S soils with $\mathrm{Pb}^{2+}\left(\mathrm{CSR}^{-} \mathrm{Pb}^{2+}\right)$. 


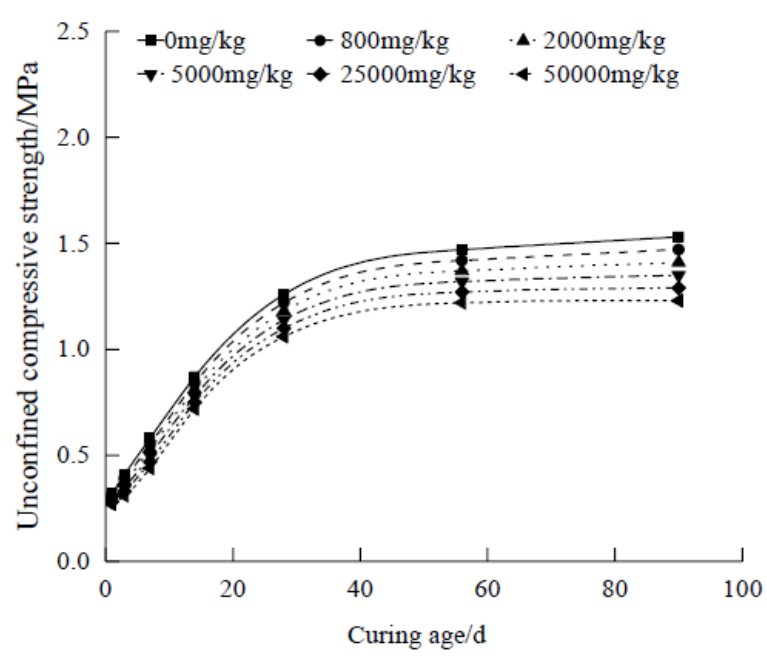

(a) $\mathrm{S}_{\mathrm{b}} / \mathrm{S}_{\mathrm{d}}=7.5 \%$

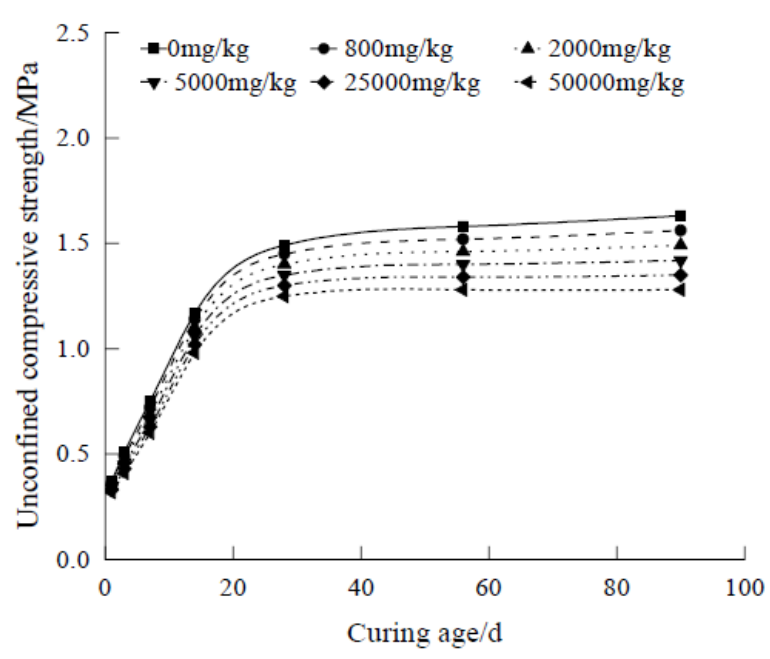

(b) $\mathrm{S}_{\mathrm{b}} / \mathrm{S}_{\mathrm{d}}=10 \%$

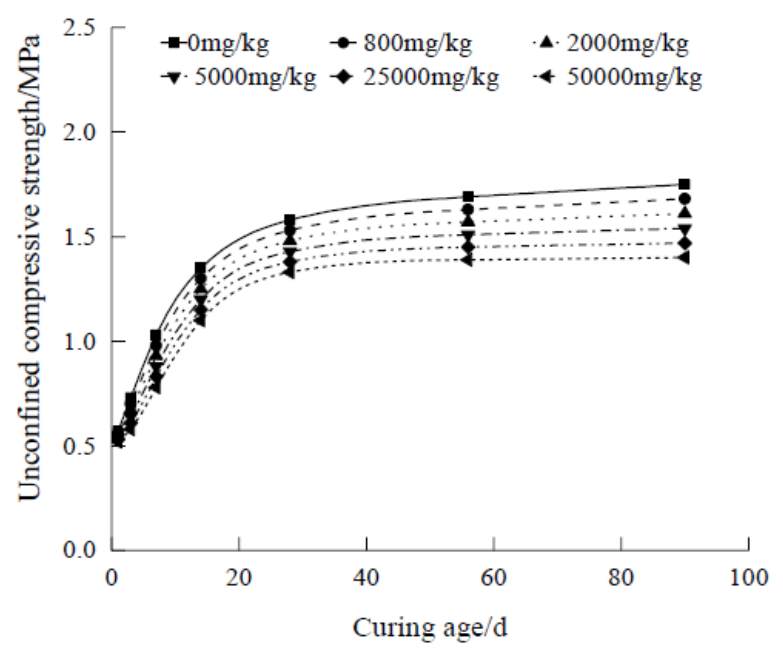

(c) $\mathrm{S}_{\mathrm{b}} / \mathrm{S}_{\mathrm{d}}=15 \%$

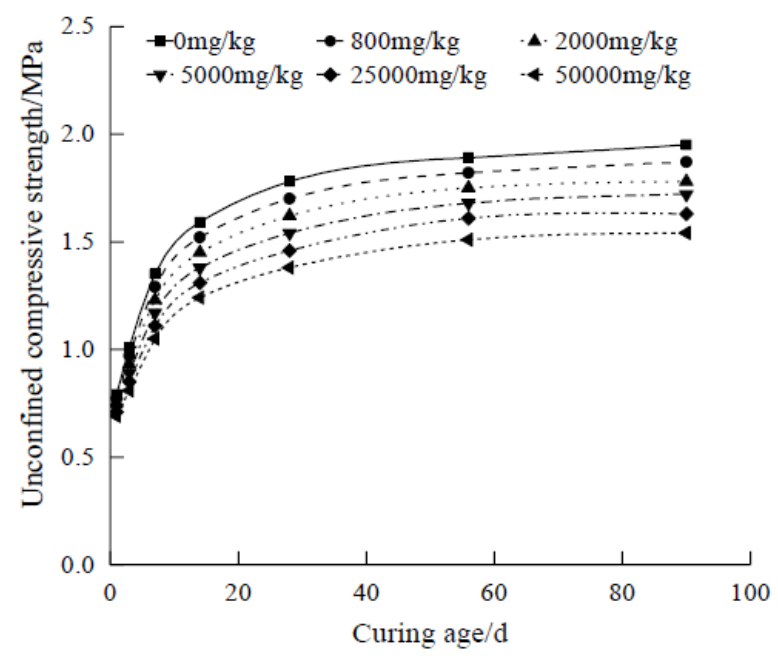

(d) $\mathrm{S}_{\mathrm{b}} / \mathrm{S}_{\mathrm{d}}=20 \%$

\section{Figure 5}

UCS development of stabilized/solidified soil samples for different $S_{b} / S_{d}$ ratio(100\% OPC). 


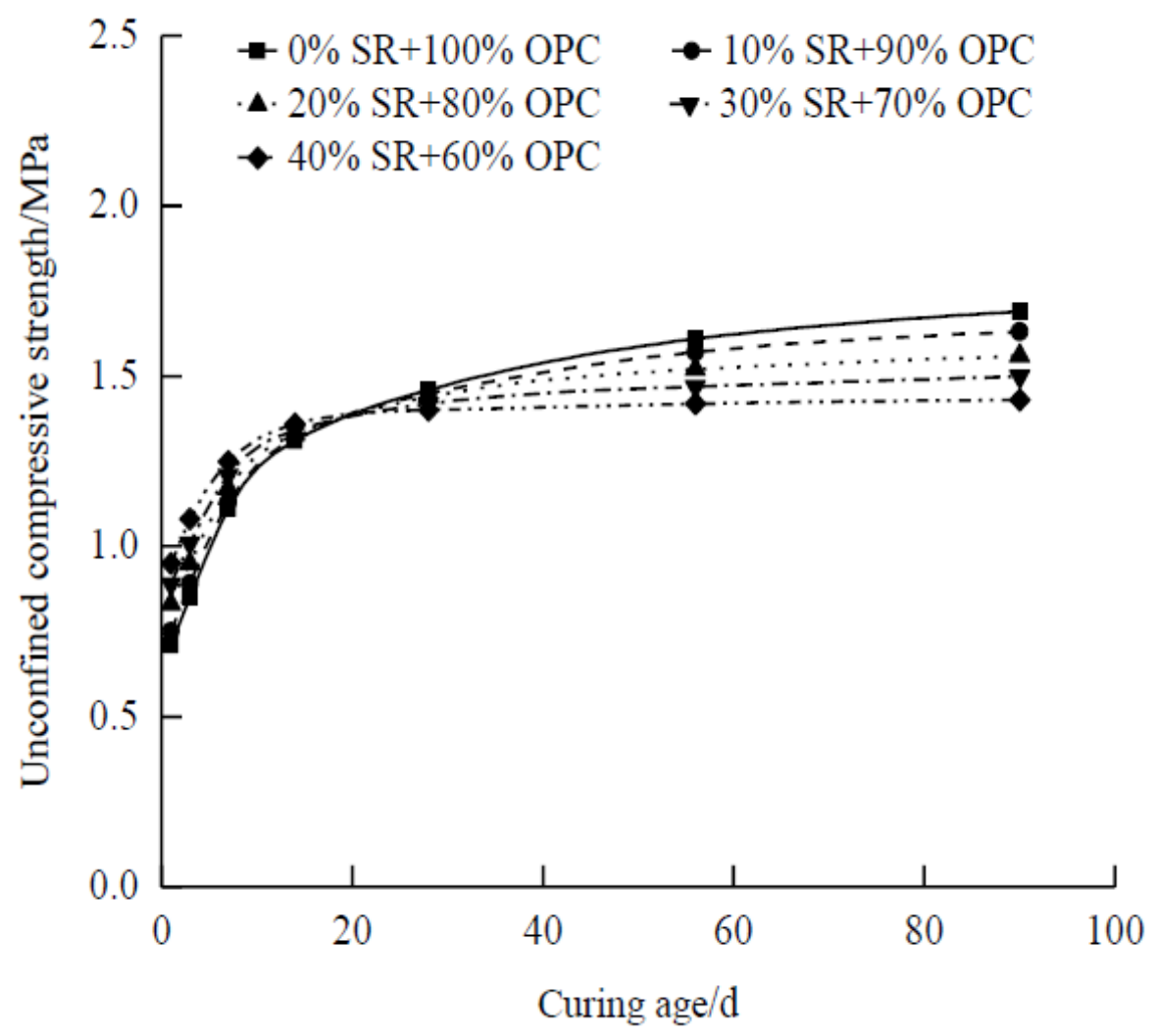

Figure 6

UCS development of stabilized/solidified soil samples for different $S_{S} / S_{b}$ ratio( $\left.S_{b} / S_{d}=20 \%, W=50000 \mathrm{mg} / \mathrm{kg}\right)$.

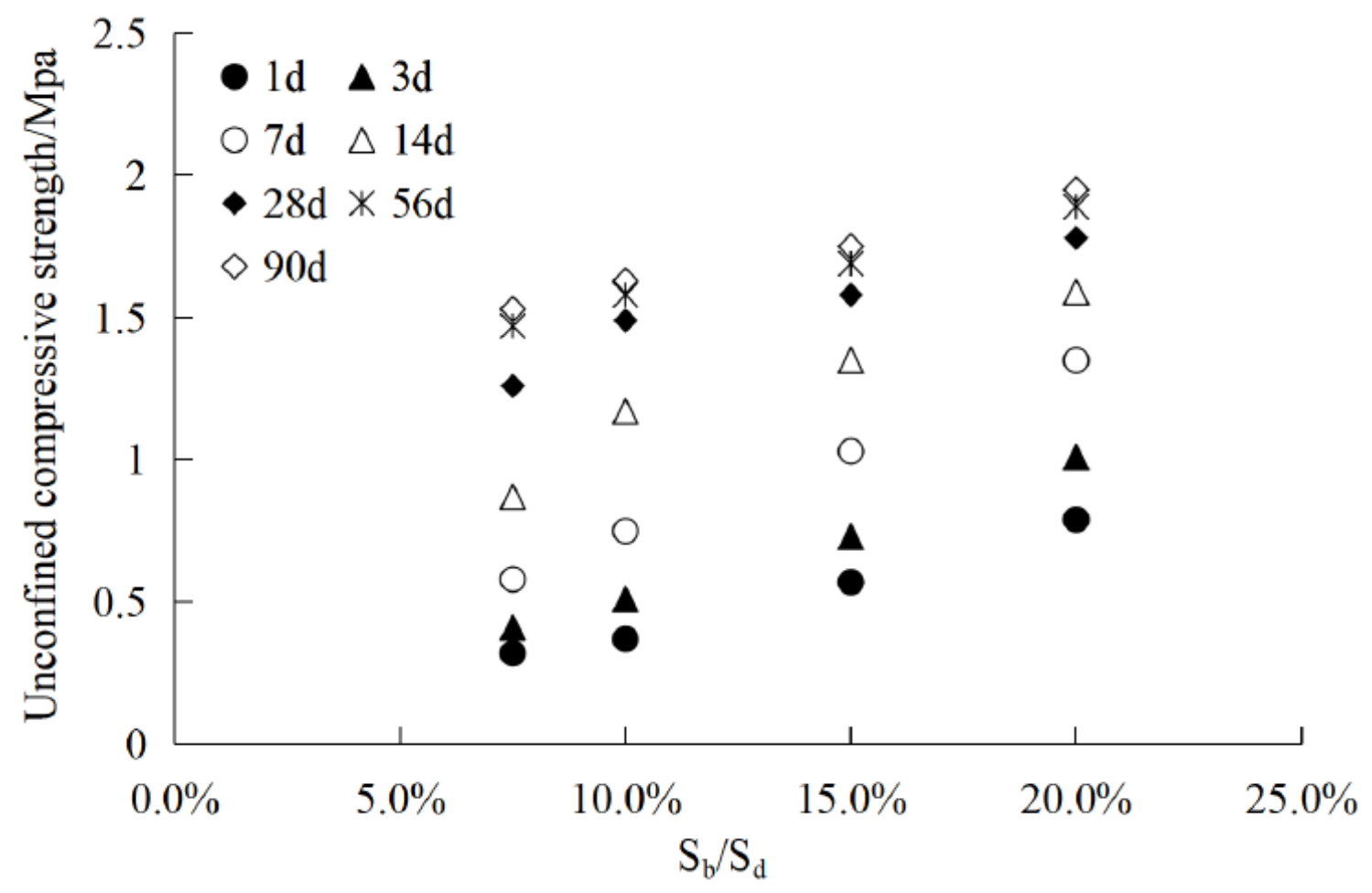

Figure 7

Growth of unconfined compressive strength with $\mathrm{S}_{\mathrm{b}} / \mathrm{S}_{\mathrm{d}}$ ratio. 

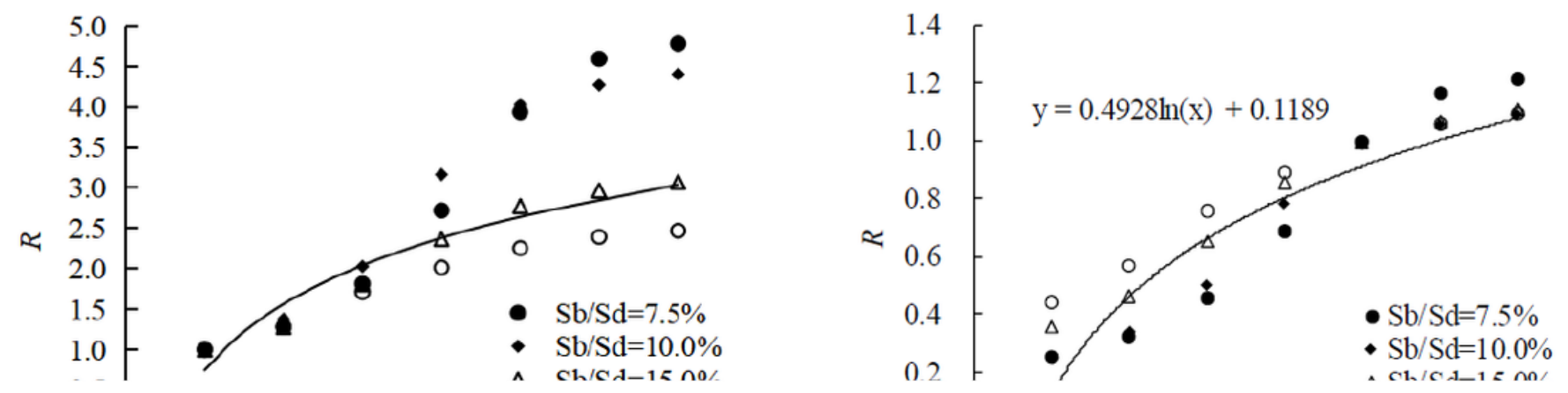

\section{Figure 8}

Relationship between strength ratio and age. 


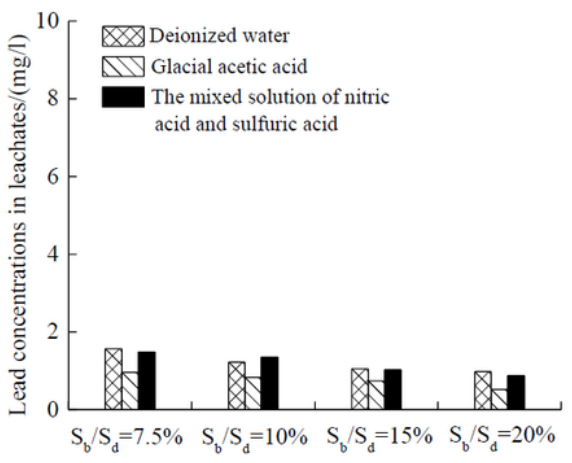

(a) $\mathrm{W}_{\mathrm{P}}=800 \mathrm{mg} / \mathrm{kg}$

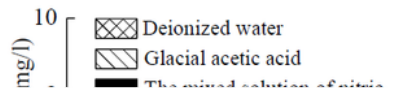

\section{Figure 9}

Lead concentrations in crushed block leachates for different $S_{b} / S_{d}$ ratio(100\% OPC). 


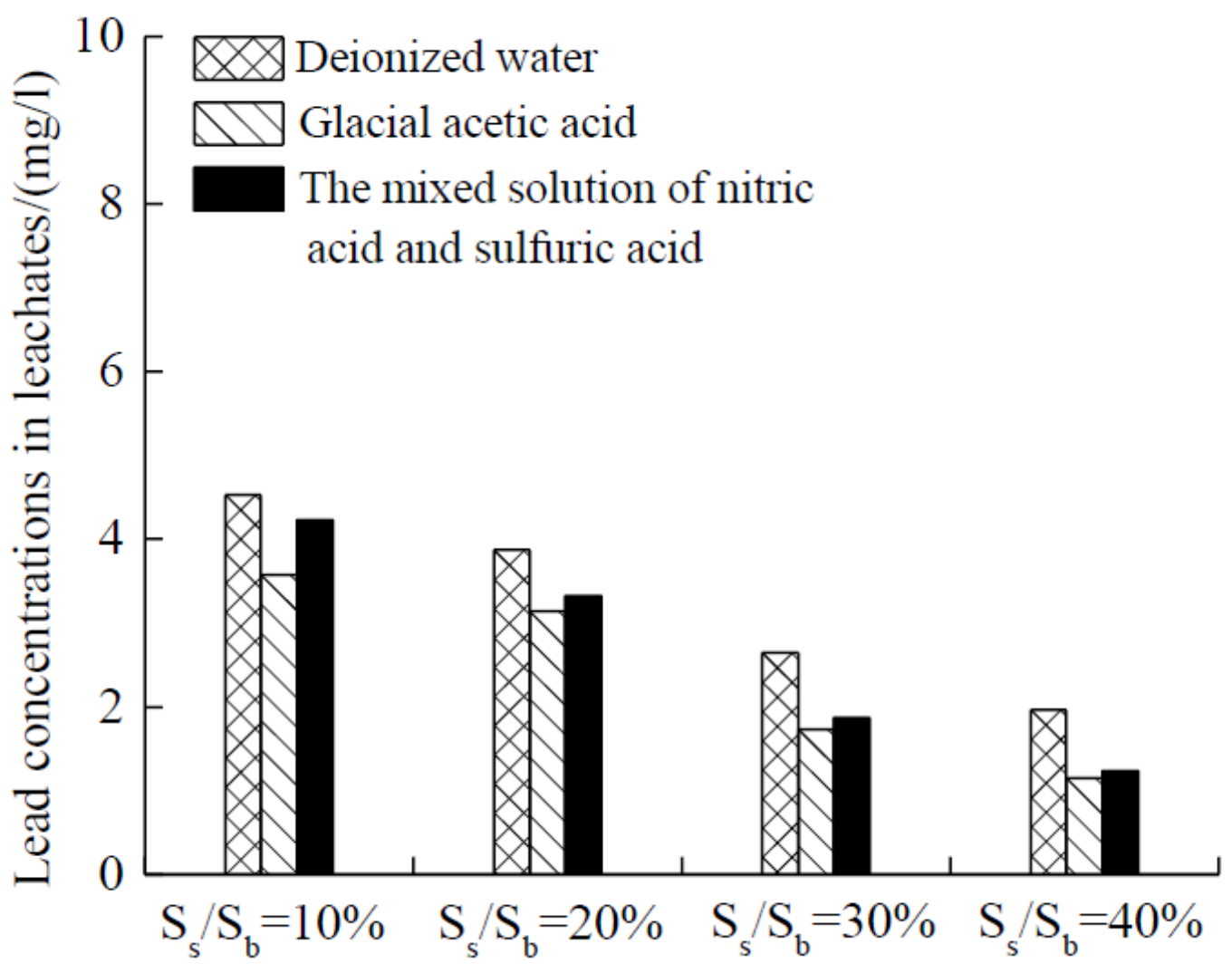

Figure 10

Lead concentrations in crushed block leachates for different Ss $/ \mathrm{Sb}$ ratio(Sb/Sd=20\%,WP=50000mg $/ \mathrm{kg}$ ).

\section{Supplementary Files}

This is a list of supplementary files associated with this preprint. Click to download.

- Scheme1.png 